\title{
Regulation and Characterization of Mutants of fixABCX in Rhizobium leguminosarum
}

\author{
Isabel U. C. Webb, ${ }^{1,2}$ Jiabao Xu, ${ }^{3}$ Carmen Sánchez-Cañizares, ${ }^{1}$ Ramakrishnan Karunakaran, ${ }^{2}$ \\ Vinoy K. Ramachandran, ${ }^{1}$ Paul J. Rutten, ${ }^{1}$ Alison K. East, ${ }^{1}$ Wei E. Huang, ${ }^{3}$ Nicholas J. Watmough, ${ }^{4}$ \\ and Philip S. Poole 1,2, $^{1,}$ \\ ${ }^{1}$ Department of Plant Sciences, University of Oxford, South Parks Road, Oxford OX1 3RB, U.K. \\ ${ }^{2}$ Department of Molecular Microbiology, John Innes Centre, Norwich Research Park, Norwich NR4 7UH, U.K. \\ ${ }^{3}$ Department of Engineering, University of Oxford, Parks Road, Oxford OX1 3PJ, U.K. \\ ${ }^{4}$ School of Biological Sciences, University of East Anglia, Norwich Research Park, Norwich, Norfolk NR4 7TJ, U.K.
}

Accepted 9 June 2021.

Symbiosis between Rhizobium leguminosarum and Pisum sativum requires tight control of redox balance in order to maintain respiration under the microaerobic conditions required for nitrogenase while still producing the eight electrons and sixteen molecules of ATP needed for nitrogen fixation. Fix$\mathrm{ABCX}$, a cluster of electron transfer flavoproteins essential for nitrogen fixation, is encoded on the Sym plasmid (pRL10), immediately upstream of nifA, which encodes the general transcriptional regulator of nitrogen fixation. There is a symbiotically regulated NifA-dependent promoter upstream of fixA ( $\left.\mathbf{P}_{\text {nifAl }}\right)$, as well as an additional basal constitutive promoter driving background expression of nifA $\left(\mathbf{P}_{\text {nifA2 }}\right)$. These were confirmed by $\mathbf{5}^{\prime}$-end mapping of transcription start sites using differential RNA-seq. Complementation of polar fixAB and fix $X$ mutants ( $\mathrm{Fix}^{-}$strains) confirmed expression of nifA from $\mathbf{P}_{\text {nifAI }}$ in symbiosis. Electron microscopy combined with single-cell Raman microspectroscopy characterization of fix $A B$ mutants revealed previously unknown heterogeneity in bacteroid morphology within a single nodule. Two morphotypes of mutant fixAB bacteroids were observed. One was larger than wild-type bacteroids and contained high levels of polyhydroxy-3-butyrate, a complex energy/reductant storage product. A second bacteroid phenotype was morphologically and compositionally different and resembled wild-type infection thread cells. From these two characteristic fixAB mutant bacteroid morphotypes, inferences can be drawn on the metabolism of wild-type nitrogen-fixing bacteroids.

${ }^{\dagger}$ Corresponding author: P. S. Poole; philip.poole@plants.ox.ac.uk

Funding: This research was funded by Engineering and Physical Sciences Research Council grants EP/M002403/1 and EP/M02833X/1, Biotechnology and Biological Sciences Research Council grants BB/ J014524/1, BB/M011224/1, and BB/N003608/1, and Natural Environment Research Council grant NE/M002934/1.

Data generated in this study is available upon request. The complete differential RNA-seq raw dataset has been submitted to the Short Read Archive (BioProject accession number PRJNA667846).

*The $\boldsymbol{e}$-Xtra logo stands for "electronic extra" and indicates there is supplementary material published online.

The author(s) declare no conflict of interest.

Copyright $\odot 2021$ The Author(s). This is an open access article distributed under the CC BY 4.0 International license.
Keywords: bacteroid morphology, dRNA-seq, electron transfer flavoproteins, fix $A B C X$, NifA regulation, nitrogen fixation, PHB, polyhydroxy-3-butyrate, redox balance, Rhizobium leguminosarum bv. viciae, single-cell Raman microspectroscopy (SCRM)

Nitrogen fixation by Rhizobium-legume symbioses provide a significant fraction of the biologically available nitrogen in the biosphere, making it agronomically and ecologically important. Inside nodules on legume roots, dinitrogen is reduced to ammonium by specialized bacterial cells (bacteroids) (Udvardi and Poole 2013). Upon bacterial infection of legumes such as pea, rhizobia enter the host via plant-derived infection threads before release into plant cells and terminal differentiation into bacteroids. Bacteroid differentiation is accompanied by morphological and transcriptional changes as the bacteria change shape and increase in size (Mergaert et al. 2006), undergoing genome endoreduplication to become polyploid. Expression of bacterial genes involved in motility and cell division is down-regulated, while expression of those involved in nitrogen fixation is up-regulated (Barnett et al. 2004; Becker et al. 2004; Karunakaran et al. 2009; Tsukada et al. 2009). Most genes required for successful symbiosis, nodulation $(n o d)$, and nitrogen fixation (nif and fix) are clustered on a symbiotic plasmid (pSym) or on the chromosome as genomic islands, the genetic organization of which varies between bacterial strains and host plants (Finan 2002; Poole et al. 2018)

The genes in the fixABCX cluster, encoded on pSym or on symbiotic islands, are widely distributed in rhizobia and have been shown to be essential for nitrogen fixation in several rhizobia, including Ensifer meliloti (Batut et al. 1985; Dusha et al. 1987; Earl et al. 1987; Hirsch and Smith 1987), Bradyrhizobium japonicum (Gubler et al. 1989), and Azorhizobium caulinodans (Kaminski et al. 1988). FixA and FixB show homology to the $\beta$ and $\alpha$ subunits, respectively, of mammalian electron transfer flavoproteins (ETFs) (Arigoni et al. 1991; Tsai and Saier 1995), while FixCX shows homology to the ETF cognate acceptor ETF-quinone oxidase (ETF-QO) (Edgren and Nordlund 2006; Watmough and Frerman 2010). ETF-QO proteins typically pass electrons onwards to terminal electron acceptors and are highly conserved across the kingdoms of life. It has been suggested that FixABCX is involved in electron transfer to nitrogenase (Terpolilli et al. 2016) and has been shown experimentally that purified FixABCX from Azotobacter vinelandii bifurcates electrons from NADH to flavodoxin and coenzyme Q (CoQ) (Ledbetter et al. 2017). Electron bifurcation from a two-electron 
donor flavin adenine dinucleotide to a single electron highpotential acceptor CoQ as well as a single low-potential acceptor (flavodoxin or, potentially, ferredoxin), makes the overall reaction energetically favorable (Lubner et al. 2017; Weghoff et al. 2015). A variety of electron transfer pathways to nitrogenase are found in the genomes of diazotrophs (Garcia Costas et al. 2017; Poudel et al. 2018). Within nitrogen-fixing bacteroids, the high electron requirement of nitrogen fixation requires careful coordination with other cellular processes to maintain the correct redox balance. Carbon storage sinks, such as polyhydroxy-3-butyrate (PHB), glycogen, and lipids, have an important role in maintaining redox balance (Lodwig et al. 2005; Terpolilli et al. 2016).

The NifA transcription factor, which coordinates the expression of components of the nitrogen-fixation machinery, is essential for symbiosis across rhizobial species (Fischer et al. 1986; Hirsch and Smith 1987; Labes et al. 1993). NifA is a member of the enhancer-binding protein family and acts together with its cognate sigma factor $\left(\sigma^{54}\right)$ RpoN (Salazar et al. 2010; Sullivan et al. 2013). The NifA-RpoN regulon acts on -24/-12 type promoters recognizing canonical upstream activator sequences (UAS) bound by NifA (5'-TGT-N $\left.10^{-A C A-3}\right)$. In Rhizobium leguminosarum bv. viciae, many genes on pSym, including those encoding nitrogenase (NifHDK) and the electron transfer protein cluster FixABCX, are under NifA control (Agron et al. 1992; Salazar et al. 2010), with nifH and fixA among the most highly upregulated genes in mature bacteroids compared with free-living bacteria (Karunakaran et al. 2009). Also under NifA control are genes of pathways less directly involved with symbiosis and are often strain- or species-specific, e.g., uptake hydrogenases (Brito et al. 1997) and rhizopine synthesis (Heinrich et al. 2001).

The microaerobic conditions found in nodules are needed for optimum functioning of the oxygen-labile nitrogenase and are facilitated by the presence of the oxygen-binding protein leghemoglobin (Ott et al. 2005). Rhizobia exhibit tight oxygendependent control of expression of genes involved in nitrogen fixation, the final stages of which are mediated by NifA (Rutten and Poole 2019). Regulation of NifA occurs at both the transcriptional level and through modulation of its activity posttranscriptionally, although this varies depending on the rhizobial species (Rutten and Poole 2019). In Ensifer meliloti, there is transcriptional control of nifA through an oxygen-responsive regulator cascade consisting of FixLJ-FixK (David et al. 1988; Ditta et al. 1987). In Ensifer meliloti, there is a FixJ binding site immediately upstream of nifA (Ferrières and Kahn 2002) that enables partial expression of nifA under low oxygen concentrations in laboratory cultures. In Bradyrhizobium japonicum, nifA expression is not regulated by FixLJ but, instead, by the redoxresponsive RegS-RegR system (Bauer et al. 1998; Lindemann et al. 2007). R. leguminosarum bv. viciae has a different regulatory cascade consisting of hFixL-FxkR and FixK (ZamoranoSánchez et al. 2012). It also employs an additional oxygenresponsive protein, FnrN, that is essential for nitrogen fixation (Gutiérrez et al. 1997). However, there are no binding sites upstream of nifA to indicate it is regulated by either hFixL-FxkR or FnrN in $R$. leguminosarum. This begs the question how is nifA expression kick-started? Studies on expression of nifA in $R$. leguminosarum bv. viciae UPM791 showed that, under symbiotic conditions, a 5.1-kb mRNA is generated covering the gene cluster orf71 orf79 fixW orf5 fixABCX nifAB (Martínez et al. 2004). The transcription start site (TSS) was experimentally determined to be upstream of orf71, and an RpoN-dependent promoter including the NifA UAS (91 bp upstream of transcription start) was mapped $\left(\mathrm{P}_{n i f A 1}\right)$. A second promoter $\left(\mathrm{P}_{n i f A 2}\right)$ providing basal levels of nifA expression and lying upstream of the fix-nifA intergenic region (IGR) was postulated by Martínez et al. (2004).
We observed that, in $R$. leguminosarum bv. viciae 3841 (Rlv3841), nifA expression is strongly upregulated during symbiosis compared with that in free-living bacteria (Karunakaran et al. 2009). We also demonstrate that there is autoregulation of nifA expression from a promoter upstream of the putative fix$A B C X$ operon during symbiosis with its host, Pisum sativum. Under free-living conditions, we can detect oxygen-independent basal expression, possibly from one or more promoters within fix $C$, and show that, during symbiosis, this basal expression is sufficient to maintain nitrogen fixation, albeit at a reduced rate. We have investigated the effects of fix $A B C X$ mutations in Rlv3841, confirming that these genes have an essential role in nitrogen-fixing symbiosis with its host $P$. sativum. Ultrastructural analysis of these $\mathrm{Fix}^{-}$bacteroids show changes during development that lead to heterogeneous bacteroids within nodules, differing in morphology and composition. These ultrastructural studies are supported by biochemical characterization of these two cell phenotypes by single-cell Raman microspectroscopy (SCRM). Implications for the metabolism of bacteroid storage compounds are explored.

\section{RESULTS}

\section{Promoters are present in the fix $A B C X n i f A B$ region upstream of fixA and nifA.}

In Rlv3841, the fixABCX cluster (pRL100200 to pRL100197) is located upstream of nifA (pRL10196), with pRL100201, divergently transcribed from pRL100200, lying $1,070 \mathrm{bp}$ upstream (Fig. 1). The organization of this cluster on Rlv3841s pSym plasmid is different from that of the well-studied $R$. leguminosarum UPM791 (Martínez et al. 2004), with Rlv3841 lacking orf71 orf79 fixW and orf5 immediately upstream of fixA. From sequence analysis, it is apparent that the first gene in the fixABCX cluster, fixA, has two upstream putative UAS (5'-TGT$\mathrm{N}_{10}$-ACA-3') at positions -725 (distal) and -148 (proximal) as well as one putative RpoN-binding site (5'-TGGCAC-N $6^{-}$ TGCT-3') at -68 (Fig. 1B) (Salazar et al. 2010). To investigate this IGR, it was cloned in its entirety, as well as different truncated versions lacking the putative UAS and RpoN-binding sites, upstream of a promoterless $\operatorname{lux} C D A B E$ cluster in the Lux bioreporter plasmid pIJ11268 (Frederix et al. 2014). Potential promoter regions PfixA.1 to PfixA.6 (Fig. 1B) were cloned, giving plasmids pPfixA.1 to pPfixA.6 (Supplementary Table S1), and were conjugated into wild-type Rlv3841. During free-living bacterial growth in rich medium (tryptone yeast [TY]) under aerobic conditions, of these potential promoters, PfixA.6 showed no luminescence above background at either 21 or $1 \% \mathrm{O}_{2}$, while luminescence of PfixA.1 to PfixA.5 $\left(<0.5 \times 10^{3}\right.$ relative luminescence units per optical density at $\left.595 \mathrm{~nm}\left[\mathrm{RLU} / \mathrm{OD}_{595}\right]\right)$ was $>2$ orders of magnitude lower than the positive control (Pneo) (approximately 0.5 to $2 \times 10^{5}$ RLU/OD $_{595 \mathrm{~nm}}$ ) (Fig. 1C). However, in pea nodules (in planta) PfixA.1 expression (approximately $2.5 \times 10^{3}$ counts per second per nodule [cps/nodule]) was as high as the Pneo positive control (Fig. 1D). This result agrees with previous microarray analyses showing that fixA is expressed only during symbiosis and not during free-living growth (Karunakaran et al. 2009). Both the proximal $(-148)$ UAS and the single (-68) RpoN-binding sites were required for promoter activity in bacteroids, as their deletion in PfixA.5 and PfixA.6, respectively, abolished luminescence. Interestingly, regions lacking the distal (-725) UAS site (PfixA.2, PfixA.3, and PfixA.4, approximately $6 \times 10^{4}$ to $1.1 \times 10^{5} \mathrm{cps} /$ nodule) gave higher luminescence than the full-length PfixA.1, suggesting competitive effects between these two UASs or a change in topology of the plasmid-cloned fragment leading to changes in expression. This distal UAS may be involved in regulation of the divergent gene (pRL100201, encoding a nonessential 
uncharacterized protein) that has been shown to be highly expressed under symbiotic conditions (Karunakaran et al. 2009). Expression from PfixA.3 is lower than from PfixA.4, suggesting that the region from -709 to -175 may facilitate NifA binding or have additional regulatory effects. However, PfixA.3 (283 bp) defines the minimal region needed for at least wild-type levels of fixA expression (Fig. 1).
Previous studies in $R$. leguminosarum UPM791 mapped the main NifA-regulated promoter $\mathrm{P}_{\text {nifAl }}$ to a location upstream of orf71 within the gene cluster containing nifA (Martínez et al. 2004). Although Rlv3841 gene organization is different (lacking the four genes upstream of UPM791 fixA) the nucleotide sequence of the 250 bp directly upstream of Rlv3841 fixA shows $99.95 \%$ identity to the region upstream of orf71 in UPM791,
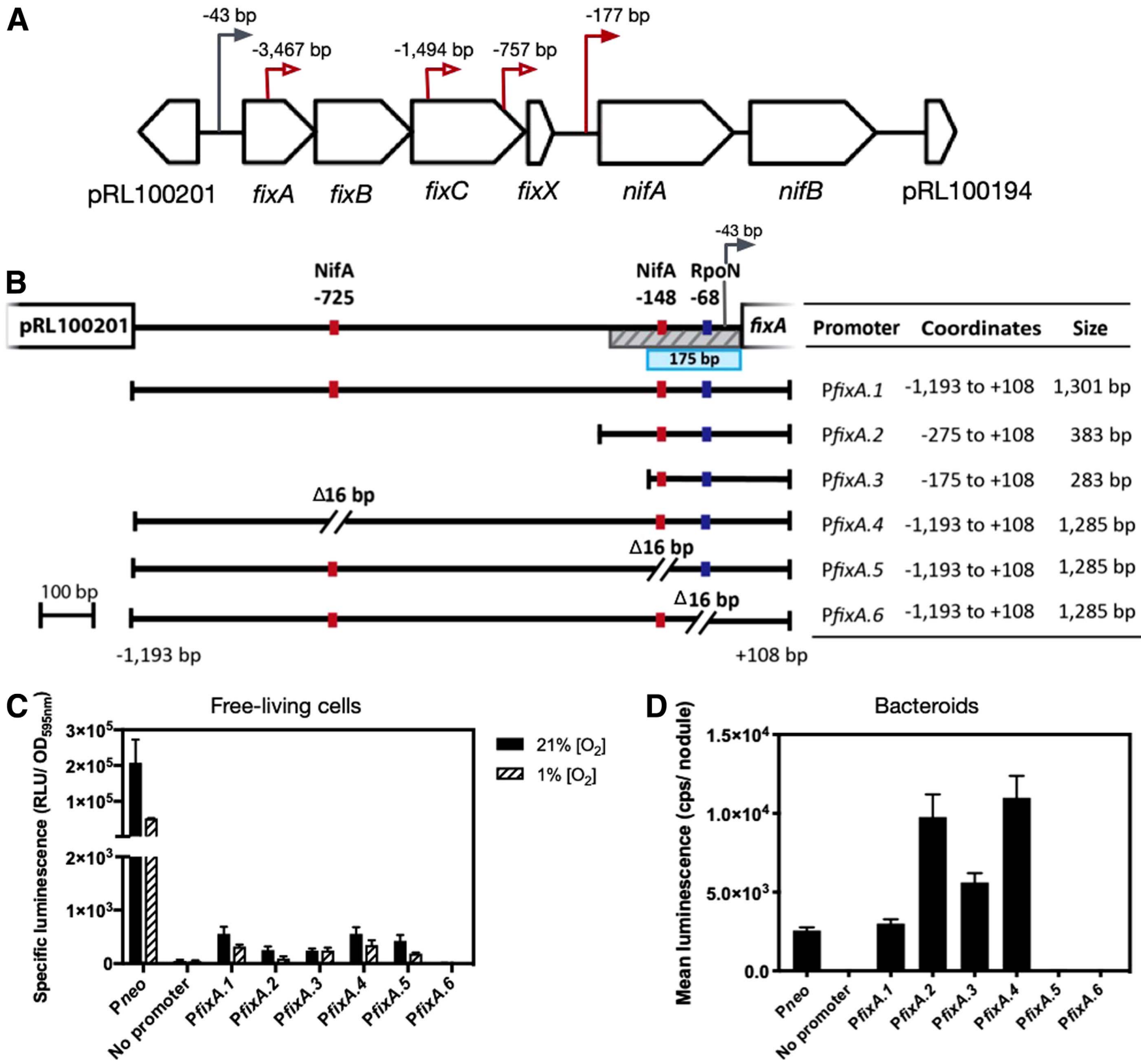

Fig. 1. Genetic map of fix $A B C X$ and nifA gene clusters and investigation of the promoter activity of the region upstream of fixABCX. A, Genetic map of fixABCX and nifA on pRL10 of Rlv3841. Transcription start sites (TSS) are indicated with a filled arrow for primary start sites and an empty arrow for secondary start sites. The position of the TSS labeled with a gray arrow ( $-43 \mathrm{bp}$ ) is given relative to the fixA open reading frame (ORF), while the positions of the TSS indicated by numbered red arrows are given relative to the nifA ORF. B, The intergenic region between pRL100201 and fixA harboring two upstream putative upstream activator sequence sites $\left(5^{\prime}-\mathrm{TGT}-\mathrm{N}_{10}-\mathrm{ACA}-3^{\prime}\right)$, indicated by red boxes at positions -725 and -148 , and one putative RpoN-binding site $\left(5^{\prime}\right.$-TGGCAC-N $6_{6}$ TGCT- $\left.3^{\prime}\right)$, indicated by a blue box at -68 (positions relative to the start site of nifA). The hatched area indicates a 250-bp region showing 99.95\% identity to that sequenced by Martínez et al. (2004), despite being in a different location. The minimal 175-bp region identified to drive expression of fixA is shown with a blue rectangle. Lines below indicate fragments from the Rlv3841 genome cloned to assess promoter activity (PfixA.1 to PfixA.6), with line breaks indicating that $16 \mathrm{bp}$ of the corresponding binding site have been deleted. The table indicates coordinates and sizes of these fragments. C, Maximum specific luminescence (relative luminescence units per optical density at $595 \mathrm{~nm}$ [RLU/OD 595$]$ ) driven by fragments PfixA.1 to PfixA.6 in free-living cells, with the cloned Pneo (constitutive promoter) as a positive control and the empty vector as a negative control. Assays performed in free-living cultures grown at $21 \% \mathrm{O}_{2}$ and $1 \% \mathrm{O}_{2}$. Values are the mean \pm standard error of the mean (SEM), expressed as RLU/OD 595 . Biological replicates: $n=9$ for $21 \% \mathrm{O}_{2}, n=6$ for $1 \% \mathrm{O}_{2}$. D, Nodule mean luminescence driven by fragments PfixA.1 to PfixA.6 in pea nodules at 21 days postinoculation, with the same controls as C; luminescence values expressed as relative counts per second per nodule (cps/nodule) \pm SEM, $n=30$ to 70 . 
including the RpoN- and UAS sites (Martínez et al. 2004) (Fig. 1A).

Differential RNA-seq (dRNA-seq) was performed on Rlv3841 at different growth and developmental stages, i.e., freeliving growth in 14 different media, in the rhizosphere of peas and as bacteroids, from the base, body, and tips of pea nodules at 28 days postinoculation (dpi), allowing the mapping of TSSs. The results and TSSs identified within this region of pRL10 are shown in Table 1. Upstream of fixA at position $-43 \mathrm{bp}$, there is a TSS in samples from the body and tips of 28-dpi nodules (Fig. 1A; Table 1). This agrees very well with the location of the transcription initiation site of the UPM791 $\mathrm{P}_{\text {nifAl }}$ promoter (Martínez et al. 2004), which lies only 2 nt further upstream. We designated this Rlv3841 promoter $\mathrm{P}_{n i f A l}$ to maintain consistency of nomenclature.

However, this leaves the question of whether, as in UPM791, there is also a basal promoter upstream of nifA enabling lowlevel background expression that can be upregulated in the nodule when required (possibly triggered by low $\mathrm{O}_{2}$ ). In UPM791, $\mathrm{P}_{\text {nifA2 }}$ was mapped to the fixX-nifA IGR upstream of nifA (Martínez et al. 2004). It is possible that this replaces FixK regulation of nifA, which is observed in Ensifer meliloti but absent from R. leguminosarum (David et al. 1988; Ditta et al. 1987). To answer this, several regions of DNA immediately upstream of nifA (PnifA.1 to PnifA.6) were cloned in the Lux reporter plasmid pIJ1268 (Fig. 2A). The largest fragment cloned, PnifA.1, gave significant luminescence compared with background in free-living conditions at $21 \% \mathrm{O}_{2}$ (approximately $2.5 \times$ $10^{4}$ RLU/OD 595 ) (Fig. 2B). This contrasts with previous studies in $R$. leguminosarum UPM791 showing expression only within nodules (Martínez et al. 2004). In free-living Ensifer meliloti cells, nifA expression is induced by a microaerobic environment (Ditta et al. 1987), so luminescence was measured at $1 \% \mathrm{O}_{2}$ to determine whether nifA expression in Rlv3841 is affected by the oxygen tension. No significant difference is seen between the luminescence driven by cloned PnifA.1, PnifA.2, PnifA.5, and PnifA.6 at 21 and $1 \% \mathrm{O}_{2}\left(2 \times 10^{4}\right.$ to $\left.3 \times 10^{4} \mathrm{RLU}^{4} \mathrm{OD}_{595}\right)$, while luminescence is lower $\left(<1 \times 10^{4} \mathrm{RLU} \mathrm{OD}_{595}\right)$ for PnifA.3 and PnifA.4 (Fig. 2B). This would suggest that PnifA.3 and PnifA.4 lack some signal for expression present in the other cloned fragments. From examining their sequence (Fig. 2A), it is not readily apparent what this might be; although PnifA.4 is the smallest fragment, PnifA.3 is larger than both PnifA.5 and PnifA.6, which show activity (Fig. 2B and C), and PnifA.3 through PnifA.6 all contain the TSS at -177 bp (Fig. 2A). Although further experiments could be performed at even lower $\mathrm{O}_{2}$ concentrations in vitro, $R$. leguminosarum grows only poorly under such conditions and we moved on to examining biologically relevant expression in planta. Luminescence was measured in bacteroids from pea nodules at 28 dpi (Fig. 2C). Levels of luminescence from PnifA.l to PnifA.6 $\left(<1 \times 10^{3} \mathrm{cps} /\right.$ nodule [Fig. 2C]) are up to 12-fold lower than those from the cloned fragments PfixA.1 to PfixA.4 (up to $1.1 \times 10^{4} \mathrm{cps} /$ nodule [Fig. $1 C]$ ), showing that PnifA promoters (cloned regions immediately upstream of nifA) are much less active than PfixA promoters (cloned regions immediately upstream of fixA) during symbiosis. This is consistent with the entire putative fixABCXnifAB operon being autoregulated by NifA binding to $\mathrm{P}_{\text {nifAl }}$ (with TSS at -43 bp [Fig. 1]) during symbiosis, with some, potentially constitutive, nifA expression driven from the fixX-nifA IGR.

From the dRNA-seq data, transcription initiating at $-177 \mathrm{bp}$ upstream of nifA (within the fixX-nifA IGR) was found in the free-living pooled samples and in the nodule base (Table 1). Transcription starting at this site can explain the luminescence in free-living bacteria driven by cloned PnifA.1 to PnifA.6. For consistency with Martínez et al. (2004), we can make a tentative assignment of the TSS upstream of nifA at -177 bp as $\mathrm{P}_{\text {nifA2 }}$ (Figs. 1A and 2A). Examination of the nucleotide sequence upstream of $\mathrm{P}_{\text {nifA2 }}$ shows potential -35 and -10 RpoD-binding sites (Supplementary Fig. S1) with similarity to the Rlv3841 consensus, 5' -TTGNNN-N $16^{-}$CNANNT-3', predicted from genomewide TSS analysis. Only the first two nucleotides (TT) in the -35 are present, although there is excellent consensus $\left(5^{\prime}\right.$-CNANNT-3') in the -10 region and in the spacing between them $\left(-\mathrm{N}_{16^{-}}\right)$, but, overall, the lack of a clear -35 consensus would contribute to poor recognition and unstable binding, leading to low-level transcription by RpoD. Other TSSs were identified by dRNA-seq in Rlv3841 (Table 1). A secondary TSS at $-757 \mathrm{bp}$ (within the coding region of fix $\mathrm{C}$ [Fig. 2A]) is seen only in the combined sample (but is statistically significant by both analytical methods), suggesting it is active, albeit at a lower level, as it fails to be statistically relevant under any specific condition. It may be that expression from this TSS is responsible for the higher luminescence driven by PfixA.1 and PfixA.2 in nodules (Fig. 2C), as these cloned fragments are the only ones that contain this TSS (Fig. 2A). Two further secondary TSSs were identified at $-1,494$ (inside $f(x C)$ and $-3,467$ bp (inside fixA) (Fig. 2A) in the combined sample by TSSAR (Amman et al.

Table 1. Differential RNA-seq used to predict transcription start sites (TSS) in samples of Rlv3841 ${ }^{\mathrm{w}}$

\begin{tabular}{|c|c|c|c|c|c|c|c|c|c|}
\hline \multirow[b]{3}{*}{ Type $^{\mathrm{x}} / \mathrm{TSS}$ (pRL10)/ } & \multirow{3}{*}{$\begin{array}{l}\text { Relative distance } \\
\text { from gene start (bp) }\end{array}$} & \multirow[b]{3}{*}{ Gene } & \multicolumn{6}{|c|}{ TSSer } & \multirow{3}{*}{$\begin{array}{c}\text { TSSAR } \\
\text { Combined }\end{array}$} \\
\hline & & & \multirow{2}{*}{$\begin{array}{l}\text { Free-living } \\
\text { mixed }^{\mathrm{y}}\end{array}$} & \multirow[b]{2}{*}{ Rhizosphere } & \multicolumn{3}{|c|}{ Nodule area 28 dpi } & \multirow[b]{2}{*}{ Combined $^{\mathrm{z}}$} & \\
\hline & & & & & Tips & Body & Base & & \\
\hline \multicolumn{10}{|l|}{ Primary } \\
\hline 201896 & -43 & fixA & & & X & X & & X & $X$ \\
\hline 198227 & -177 & nifA & $X$ & & & & $X$ & $X$ & $X$ \\
\hline \multicolumn{10}{|l|}{ Secondary } \\
\hline 198807 & -757 & nifA & & & & & & X & $X$ \\
\hline 199544 & $-1,494$ & nifA & & & & & & & $X$ \\
\hline 201517 & $-3,467$ & nifA & & & & & & & $X$ \\
\hline
\end{tabular}

$\overline{{ }^{w}}$ Methods used for analysis were TSSer (Jorjani and Zavolan 2014) and TSSAR (Amman et al. 2014), as described by Rutten et al. (2021). dpi = days postinoculation.

$x$ A gene has a primary or main TSS and may have one or more secondary or condition-specific TSS.

${ }^{\mathrm{y}}$ Free-living mixed sample is from bacteria grown in 14 different media or conditions as follows: tryptone yeast, acid minimal salts (AMS) 20 mM succinate $10 \mathrm{mM}$ ammonia, AMS $10 \mathrm{mM}$ glucose $10 \mathrm{mM}$ ammonia, AMS $10 \mathrm{mM}$ mannitol $10 \mathrm{mM}$ ammonia, AMS $30 \mathrm{mM}$ pyruvate $10 \mathrm{mM}$ ammonia, AMS $10 \mathrm{mM}$ arabinose $10 \mathrm{mM}$ ammonia, AMS $10 \mathrm{mM}$ inositol $10 \mathrm{mM}$ ammonia, AMS 3 mM protocatechuate $10 \mathrm{mM}$ ammonia, AMS $3 \mathrm{mM}$ catechol $10 \mathrm{mM}$ ammonia, AMS $10 \mathrm{mM}$ glucose $5 \mathrm{mM}$ phenylalanine $5 \mathrm{mM} \mathrm{NH}_{4} \mathrm{Cl}$, AMS $10 \mathrm{mM}$ glucose $10 \mathrm{mM}$ ammonia, pH 5.75 , AMS $10 \mathrm{mM}$ glucose $10 \mathrm{mM}$ ammonia grown in steady state at $0.1 \% \mathrm{O}_{2}$, AMS $10 \mathrm{mM}$ glucose $10 \mathrm{mM}$ ammonia $100 \mathrm{mM} \mathrm{NaCl}$, AMS $10 \mathrm{mM}$ glucose $10 \mathrm{mM}$ ammonia $100 \mu \mathrm{M} \mathrm{H}_{2} \mathrm{O}_{2}$.

${ }^{\mathrm{z}}$ Data from all samples combined before bioinformatic analysis. 
2014) (Table 1). No obvious promoter consensus sequences are apparent in alignment of nucleotides upstream of secondary TSS at $-757,-1,494$, and $-3,467$ bp (Supplementary Fig. S1).

The fixABCX operon is essential for nitrogen fixation.

Once expression of the fix $A B C X$ operon was characterized under free-living and symbiotic conditions, we analyzed the role of this cluster in symbiosis with $P$. sativum by generating mutants. Mutants in fixAB (LMB771, fixAB::SSpec) and fixX (LMB829, fix $X:: \Omega$ Spec) were constructed by inserting an omega spectinomycin $(\Omega$ Spec) cassette, which has a polar effect on the expression of downstream genes. Nonpolar in-frame deletion mutants were made in fixAB (LMB777, $\triangle$ fixAB), fixC (OPS0280, $\Delta$ fixC), and fixX (OPS0469, $\Delta$ fixX) (cloning details are provided in Supplementary Figure S2 and strain specifications in Supplementary Table S1). As measured in plants by acetylene reduction at $28 \mathrm{dpi}$, all mutants demonstrated a $\mathrm{Nod}^{+}$ Fix $^{-}$phenotype compared with wild-type Rlv3841 (Table 2; Fig. $3 \mathrm{~A}$ through F). At $28 \mathrm{dpi}$, plants inoculated with these fix mutants were stunted and chlorotic, due to lack of nitrogen fixation, and the nodules from these nonfixing mutants were small and white, due to the lack of plant-derived leghemoglobin (Fig. $3 \mathrm{H}$ through $\mathrm{L}$ ). Using light microscopy, nodule sections stained with toluidine blue showed that the nodules from the fix $A B$ mutant were noticeably stunted $(0.5$ to $1 \mathrm{~mm})$ compared with wild-type (2 to $3 \mathrm{~mm}$ ), with fewer plant cells accommodating bacteroids (Supplementary Figs. S3 and S4).

To confirm genetic linkage of the observed phenotypes with the corresponding gene mutations, complementation experiments were performed with plasmids based on pJP2 (Prell et al. 2002). The stability of this plasmid allows consistent gene expression in planta. Plasmid pJP2 is a mini-RK2 derivative with a low copy
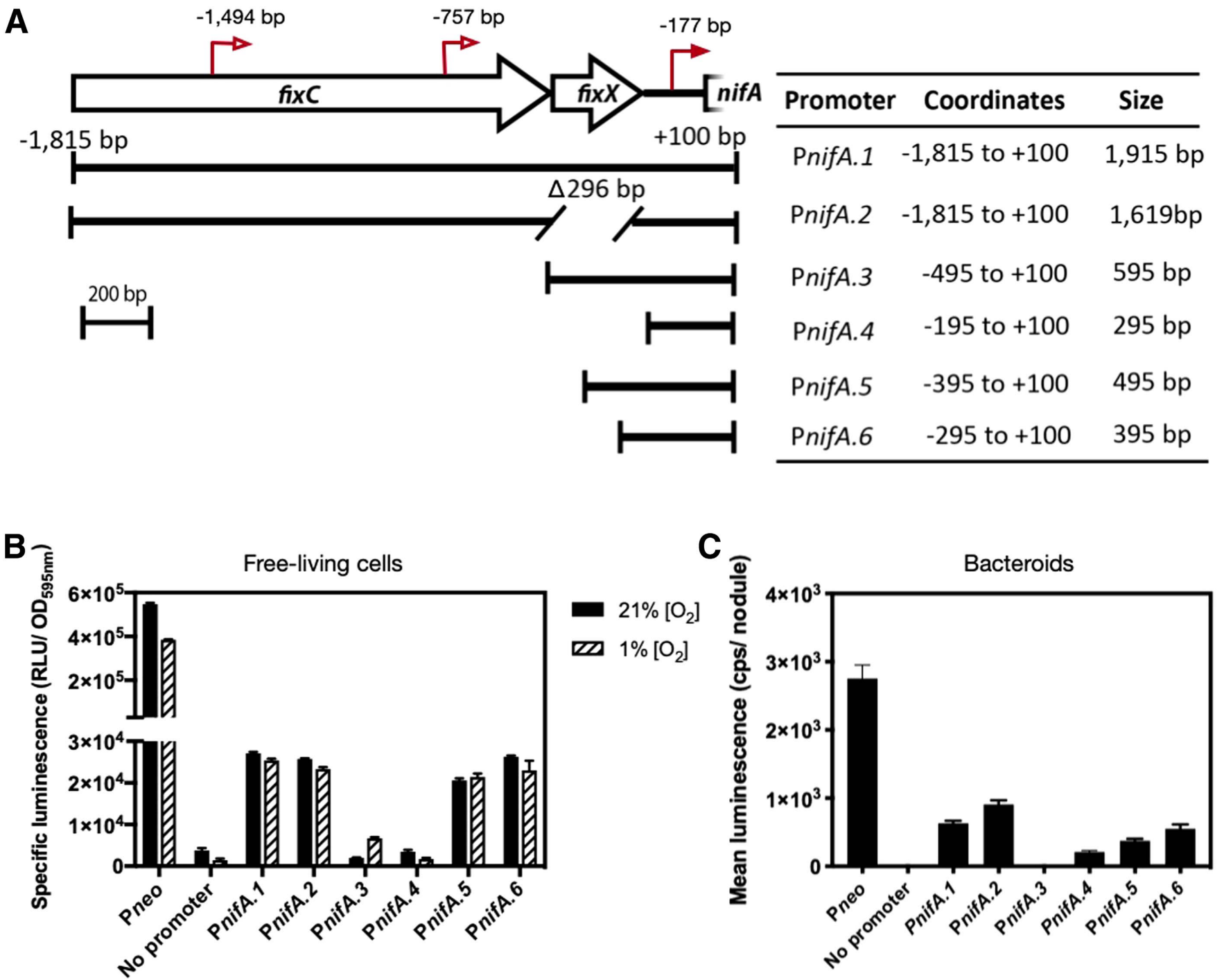

Fig. 2. Investigation of promoter activity in the region upstream of nifA. A, Map of genes immediately upstream of nifA in Rlv3841. Transcription start sites (TSS) are indicated by red arrows; filled arrows for primary start sites and empty arrows for secondary start sites with numbers indicating the coordinates relative to the first base of the nifA open reading frame (ORF). The lines below indicate the fragments cloned from the Rlv3841 genome to assess promoter activity (PnifA.1 to PnifA.6), with line breaks indicating deletion of fixX (296 bp deleted). The table indicates the coordinates relative to the start site of the nifA ORF and the sizes of cloned fragments. B, Maximum specific luminescence (relative luminescence units per optical density at 595 $\mathrm{nm}\left[\mathrm{RLU} / \mathrm{OD}_{595}\right]$ ) driven by fragments PnifA.1 to PnifA.6 cloned upstream of luxCDABE, in free-living bacterial cultures. Pneo (a constitutive promoter) was the positive control and an empty vector was the negative control. Assays done in free-living cultures grown at $21 \% \mathrm{O}_{2}$ and $1 \% \mathrm{O}_{2}$; values expressed in RLU/OD ${ }_{595} \pm$ standard error of the mean (SEM). $n=3$. C, Nodule mean luminescence (counts per second per nodule [cps/nodule]) driven by fragments PnifA.1 to PnifA.6 cloned upstream of luxCDABE in pea nodules at 21 days postinoculation, with the same positive and negative controls used in $\mathrm{B}$; luminescence expressed as cps/nodule $\pm \mathrm{SEM}, n=30$ to 70 . 
number of three to seven copies per cell in gram-negative bacteria (Kües and Stahl 1989). Plasmid pLMB811 contains cloned fix $A B$ and pLMB826 contains fixABCX, in both cases under control of the native promoter $\mathrm{P}_{\text {nifAl }}$ (Supplementary Table S1).

Acetylene reduction assays showed that the mutation in strain LMB777 (nonpolar in-frame deletion of fix $A B, \triangle f i x A B$ ) is partially complemented by cloned fixAB (pLMB811) and fully complemented by cloned fixABCX (pLMB826) (Table 2). Lack of full complementation by fix $A B$ (pLMB811) may be due to a stoichiometric imbalance or caused by the expression of fix $A B$ from a multicopy plasmid compared with fix $C X$ expression from the native pSym (pRL10). The mutation in strain LMB771 (polar fix $A B$ deletion mutant, fix $A B:: \Omega$ Spec) is not complemented by cloned fixAB (pLMB811). This mutation was also complemented by cloned fixABCX (pLMB826), albeit with a slightly reduced rate of fixation (Table 2). This confirms the operonic nature of the fixABCX cluster and is consistent with $\Omega$ Spec polarity affecting expression of downstream genes, i.e., nifA and nifB. We have shown above that nifA has one or more basal constitutive promoters causing some nifA expression in free-living cells, which would occur despite the polar $\Omega$ Spec insertion in fix $A B$.
The nonpolar fix $X$ in-frame deletion $(\triangle f i x X$, OPS0469) is fully complemented by cloned fixABCX (pLMB826) (Table 2). This could be predicted from the promoter analysis, since fix $X$ contains no promoters (Fig. 1), and secondary promoters within the fixX-nifA IGR and as well as fixC expression from $\mathrm{P}_{\text {nifAl }}$ would enable full expression of nifA. However, the polar fixX deletion ( fixX:: $\Omega$ Spec, LMB829) is not complemented by cloned fixABCX (pLMB826) (Table 2). This also agrees with our promoter analysis, as a polar fix $X$ mutant would block expression from the secondary promoters of nifA, located in fix $C$, as well as expression from $\mathrm{P}_{n i f A l}$. Further experiments were carried out to complement fixX mutations with a plasmid containing cloned fixXnifA under the control of $\mathrm{P}_{n i f A 1}$ (pOPS0303) (Supplementary Table S1). Plasmid pOPS0303 (cloned fixXnifA) complements the mutation in OPS0469 (in-frame $\Delta f i x X$ ) but is unable to complement that in LMB829 (polar fixX deletion, fixX::SSpec) (Table 2). This suggests that nifB expression is also needed for full nitrogen fixation activity. Although attempts were made to clone the fixABCXnifAB region, this proved problematic by Golden Gate cloning. The nif $B$ gene encodes an oxygen-sensitive radical $S$-adenosyl methionine enzyme providing the metal cluster

Table 2. Acetylene reduction of Rlv3841 and mutant strains on pea plants

\begin{tabular}{|c|c|c|c|c|}
\hline \multirow[b]{2}{*}{ Strain } & \multicolumn{4}{|c|}{ Complementing plasmid } \\
\hline & None & $\begin{array}{c}\text { [pLMB811] cloned } \\
\text { fixAB }\end{array}$ & $\begin{array}{c}\text { [pLMB826] cloned } \\
\text { fixABCX}\end{array}$ & $\begin{array}{c}\text { [pOPS0303] cloned } \\
\text { fixXnifA }\end{array}$ \\
\hline \multicolumn{5}{|l|}{ Experiment 1} \\
\hline Rlv3841 wild type & $3.5 \pm 0.3$ & - & - & - \\
\hline LMB771 (fixAB::SSpec) & $0.0 \pm 0.0$ & - & - & - \\
\hline LMB777 $(\triangle f i x A B)$ & $0.0 \pm 0.0$ & - & - & - \\
\hline OPS0280 ( $\Delta f i x C)$ & $0.0 \pm 0.0$ & - & - & - \\
\hline LMB829 (fixX::SSpec) & $0.0 \pm 0.0$ & - & - & - \\
\hline OPS0469 $(\Delta f i x X)$ & $0.0 \pm 0.0$ & - & - & - \\
\hline \multicolumn{5}{|l|}{ Experiment 2} \\
\hline Rlv3841 wild type & $4.1 \pm 0.4 \mathrm{a}$ & $4.3 \pm 0.3 \mathrm{a}$ & $5.2 \pm 0.3 b$ & - \\
\hline LMB771 (fixAB::SSpec) & $0.0 \pm 0.0 \mathrm{c}$ & $0.0 \pm 0.0 \mathrm{c}$ & $3.3 \pm 0.3 \mathrm{e}$ & - \\
\hline LMB777 $(\triangle f i x A B)$ & $0.0 \pm 0.0 \mathrm{c}$ & $2.0 \pm 0.2 \mathrm{~d}$ & $5.6 \pm 0.2 b$ & - \\
\hline \multicolumn{5}{|l|}{ Experiment 3} \\
\hline Rlv3841 wild type & $2.8 \pm 0.5$ & - & $3.0 \pm 0.3$ & $2.9 \pm 0.1$ \\
\hline LMB829 (fixX::SSpec) & $0.0 \pm 0.0$ & - & $0.0 \pm 0.0$ & $0.1 \pm 0.0$ \\
\hline OPS0469 $(\Delta$ fixX) & $0.0 \pm 0.0$ & - & $3.0 \pm 0.2$ & $2.4 \pm 0.1$ \\
\hline
\end{tabular}

${ }^{\mathrm{z}}$ Acetylene reduction assays were carried out on pea plants at 28 days postinoculation. Rates are in micromoles ethylene per plant/h \pm standard error of the means, $n \geq 4$. Lower case letters a to e represent statistically distinct groups $(P \leq 0.05)$ determined using one-way analysis of variance and Tukey's multiple comparisons test. - indicates not determined.
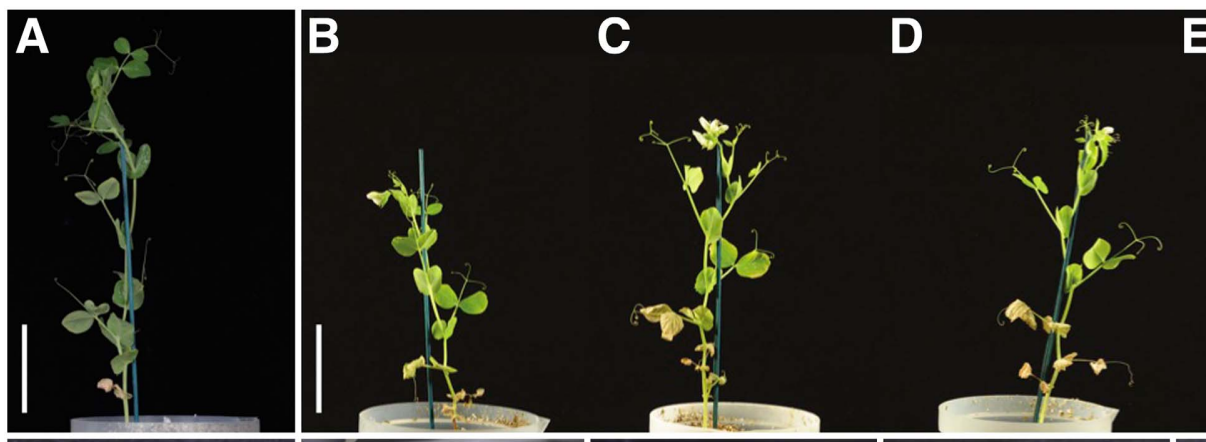

E $\quad$ F


Fig. 3. Symbiotic phenotype of Pisum sativum plants inoculated with Rhizobium leguminosarum strains at 28 days postinoculation. A to F, Plant shoot; scale bar $=60 \mathrm{~mm}$. G to $\mathbf{L}$, Root nodules; scale bar = $1 \mathrm{~mm}$. Strains are as follows: A and G, Rlv3841 (wild type); D and H, LMB771 (fixAB::SSpec); $\mathrm{C}$ and I, LMB777 ( $\triangle$ fixAB); D and J, OPS0280 ( $\triangle$ fixC); E and K, LMB829 (fixX::SSpec), and F and L, OPS0469 ( $\Delta$ fixX). 
intermediate (NifB-co) key for the biosynthesis of the active-site cofactors of nitrogenase (Burén et al. 2017). We believe this may be toxic to Escherichia coli, causing cloning to fail.

\section{fix $A B$ mutants form two morphologically distinct \\ bacteroid forms.}

The two morphotypes of bacteroids formed by LMB771 ( $f x$ $A B:: \Omega$ Spec) visualized by transmission electron microscopy (TEM) in pea nodules at $28 \mathrm{dpi}$ are shown in Figure 4. To further investigate the $\mathrm{Nod}^{+} \mathrm{Fix}^{-}$phenotype of nodules formed by fixAB mutants LMB771 and LMB777, bacteroid morphology was examined by TEM at 14, 21, and 28 dpi and was compared with that of Rlv3841 wild-type (TEM images are provided in Figure 5 and Supplementary Figures S5, S6, and S7, and bacteroid area analysis is shown in Supplementary Figure S8). In both fix $A B$ mutant strains, mature bacteroids showed drastic morphological changes from those of wild type and other
Fix $^{-}$mutants, such as a nifH mutant (strain RU3940 [Supplementary Fig. S9]), in which bacteroids are uniform in size and resemble those of wild type, although no differences were observed between the LMB771 (polar fixAB::SSpec) and LMB777 (in-frame $\triangle f i x A B$ ) mutants. In 28-dpi mature nodules formed by these mutants, two distinct bacteroid morphotypes were found. Both could be found within the same nodule, and neighboring plant cells could be filled with bacteroids of differing morphology. However, we did not find both morphotypes present within a single plant cell. We named the first morphotype LARGE, i.e., bacteroids that appeared swollen, larger than those in wild-type nodules, and filled with poly-hydroxybutyrate (PHB) (Fig. 5; Supplementary Fig. S4C, D, G, and H). Although they have a swollen appearance, they are only significantly different in size from those of wild-type bacteroids at $28 \mathrm{dpi}(P<0.001)$ (Fig. 5) and not at earlier stages of development (Supplementary Figs. S5, S6, and S7). We named the second morphotype SMALL, i.e.,

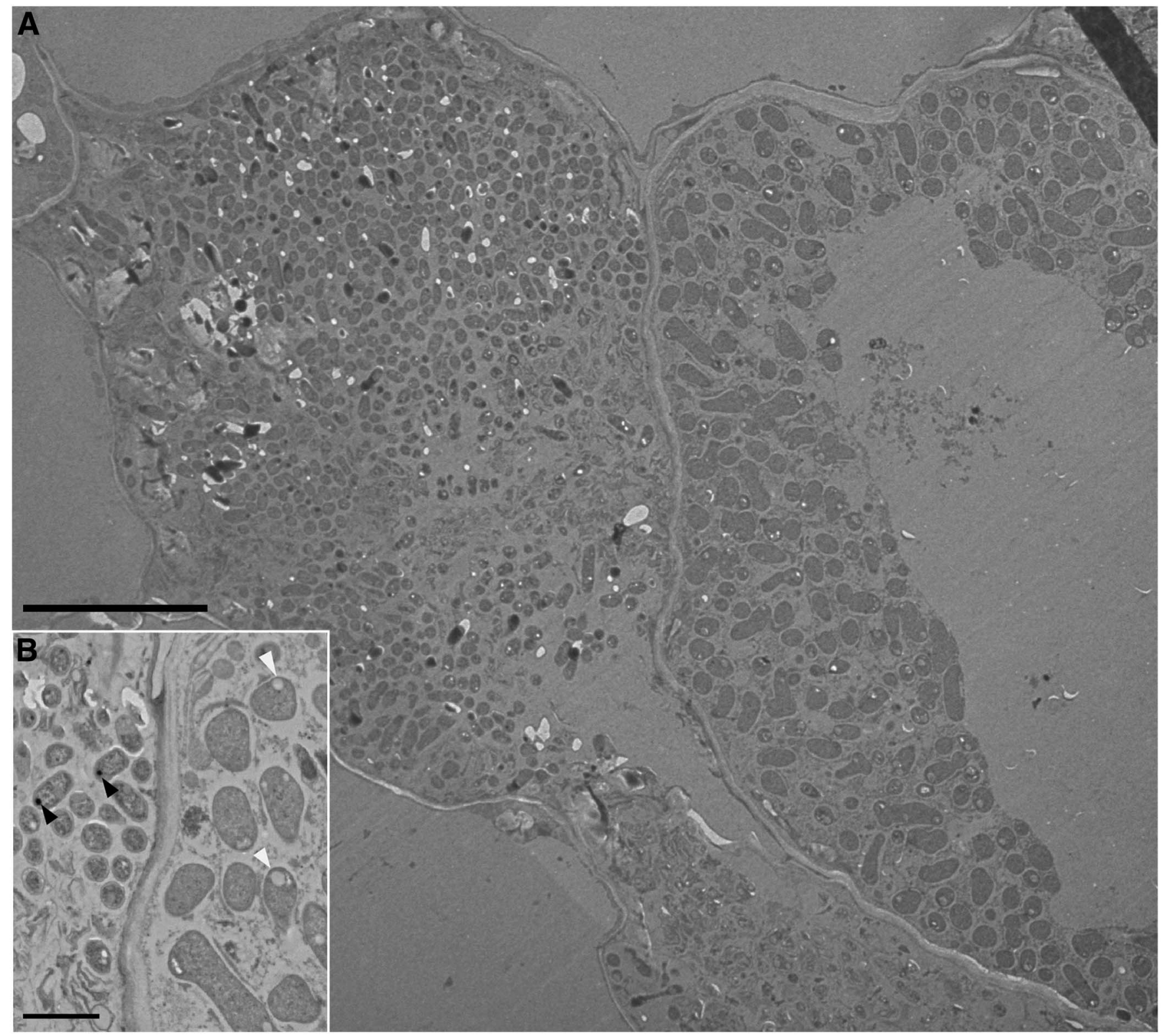

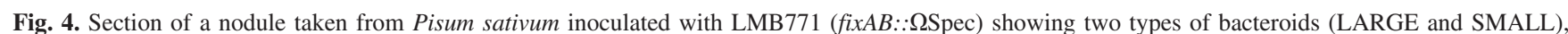
within neighboring plant cells in a nodule at 28 days postinoculation. LARGE bacteroids contain polyhydroxy-3-butyrate (PHB), which appears as electron-transparent (white) granules under electron microscopy (white arrows). SMALL bacteroids lack PHB, and, instead, electron-dense granules (black arrows) are often visible in this morphotype. A, Visualized by transmission electron microscopy (TEM) at $420 \times$. Scale bar $=10 \mu \mathrm{m}$. B, Visualized by TEM at $1,700 \times$. Scale bar $=2 \mu \mathrm{m}$. 
bacteroids smaller than wild type, with electron-dense regions (which appear black under TEM) (Fig. 5; Supplementary Fig. S5E, F, I, and J). In both LMB771 and LMB777, these electrondense inclusions appear to be frequently positioned at the poles of the cell, in clearly defined spherical granules (Supplementary Fig. $\mathrm{S} 5 \mathrm{E}, \mathrm{F}, \mathrm{I}$, and J). There are reports that attribute such inclusions to storage polymers, either polyphosphate (also known as volutin) (Friedberg and Avigad 1968; Pallerla et al. 2005) or lipids (Craig and Williamson 1972). The SMALL morphotype bacteroids are not statistically different in size from wild-type infection thread bacteria (Fig. 5). Infection thread cells can be distinguished from mature bacteroids, as bacteroids are densely packed within a plant-derived infection thread in TEM images (Supplementary Fig. S10B). During infection with wild-type Rlv3841, high levels of PHB and electron-dense granules are usually associated with infection thread cells (Supplementary Fig. S10B), and this was also observed in the fix $A B$-complemented mutants (Supplementary Fig. S10C through F). Notably, in Rlv3841 with a deletion of the chromosomal type I PHB synthase phaCl, active in freeliving and undifferentiated bacteria (Terpolilli et al. 2016), PHB granules are absent from infection thread cells, whereas the electron-dense granules are still present (Supplementary Fig. S10G and H).

\section{The two fix $A B$ bacteroid morphotypes contain different levels of energy storage compounds.}

To investigate the composition of the two bacteroid morphotypes indicated by microscopic analysis and the storage compounds they contained, SCRM was used on single bacteroid cells from mature nodules (28 dpi). In our previous work, we confirmed the presence of Raman bands associated with the polymers PHB and glycogen (bands at 1,735 and $1,050 \mathrm{~cm}^{-1}$, respectively) within Rlv3841 (Xu et al. 2017). Here, we use SCRM for the first time to examine single-cell changes in polymer levels in two distinct bacteroid cell types.

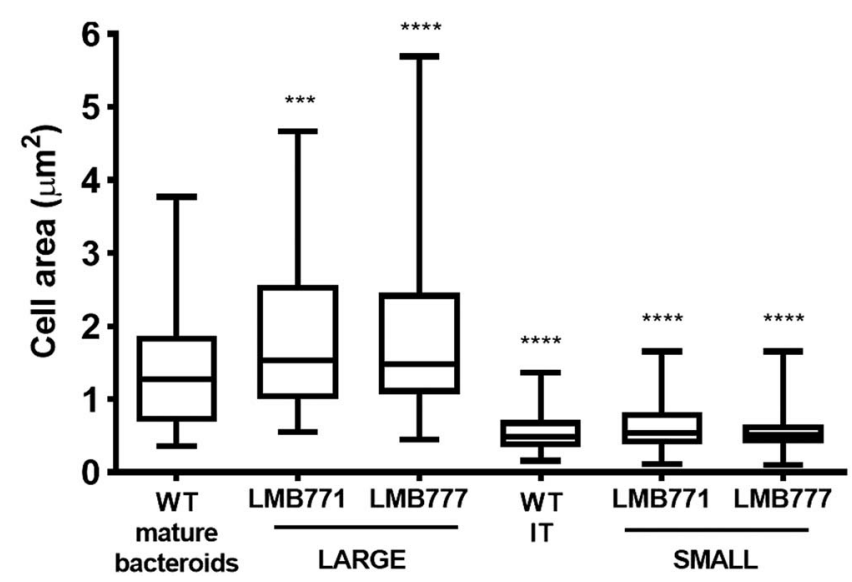

Fig. 5. Size of bacterial cells from nodules of Pisum sativum inoculated with Rhizobium leguminosarum at 28 days postinoculation. The size of cells (100 of each strain or phenotypic type), selected at random, was measured from transmission electron microscopy (TEM) images by ImageJ (of three nodules from each of three pea plants with up to three sections per nodule). All nodules were sectioned through the nitrogenfixing zone (or the widest part of the nodule, if spherical). Wild-type Rlv3841 cells were separated into bacteroids and cells in infection threads (small, densely packed, and bordered by plant-derived membranes in TEM images). LMB771 (fixAB::SSpec) and LMB777 $(\triangle$ fix $A B)$ cells were separated into LARGE and SMALL morphotypes, through size and phenotypic differences, by eye. Cell area is given in square micrometers. Boxes and whiskers show minimum to maximum values. Statistically distinct groups were determined by two-way analysis of variance and Tukey's multiple comparisons test. Four asterisks (****) indicate $P<0.0001$ and three (***) $P<0.001$.
Nodules from plants inoculated with LMB771 (polar fixAB:: $\Omega$ Spec), LMB777 (in-frame $\triangle f x A B$ mutant), and wild-type Rlv3841 were crushed and bacteroids were isolated. The bacteroid suspensions and the intracellular polymers were analyzed using SCRM. Single-cell Raman spectrum (SCRS) from fix $A B$ mutant bacteroids (28 dpi, $n=75$ ) showed there were two different phenotypes. Some bacteroids $\left(\mathrm{PHB}^{+}\right)$had a PHB band stronger than that in wild type, while others had no $\mathrm{PHB}$ band $\left(\mathrm{PHB}^{-}\right)$ (Fig. 6A). These two phenotypes $\left(\mathrm{PHB}^{+}\right.$and $\mathrm{PHB}^{-}$) corresponded to different cell sizes when compared with wild-type bacteroids (Fig. 6B). A fitted normal distribution of the measurements of single cells shows an average size of $3.31 \mu^{2}$ for $\mathrm{PHB}^{+}$and $1.39 \mu \mathrm{m}^{2}$ for $\mathrm{PHB}^{-}$, while the size of wild-type mature bacteroids is between these two $\left(2.28 \mu^{2}\right)$. Quantification of PHB in wild-type Rlv3841 and fix $A B$ mutant bacteroids is shown in Figure 7A. Quantification of glycogen levels by SCRM reveals fix $A B$ mutant bacteroids with a $\mathrm{PHB}^{+}$phenotype show significantly higher levels of glycogen, while those with a $\mathrm{PHB}^{-}$phenotype show lower glycogen levels than wild type (Fig. 7B).

Organic polyphosphate, another energy storage molecule, has been described as appearing as small electron-dense granules in TEM images (Bode et al. 1993; Craig and Williamson 1972; Pallerla et al. 2005). To characterize the electron-dense granules we observed in SMALL fixAB mutant bacteroids, a polyphosphate mutant (strain OPS0706) was generated by disrupting the gene encoding a polyphosphate kinase (ppk, RL1599). Quantification of polyphosphate by $4^{\prime}, 6$-diamidino-2-phenylindole staining revealed a 10-fold reduction in polyphosphate levels in OPS0706 compared with wild-type Rlv3841, although the growth rate of the mutant and its ability to fix nitrogen was unaffected (Supplementary Fig. S11A through C). Using this mutant, we were able to identify a Raman band at $1,172 \mathrm{~cm}^{-1}$ as that from polyphosphate (Supplementary Fig. S11E) and to quantify the levels in wild-type and mutant strains (Supplementary Fig. S11D). Quantification of polyphosphate levels by SCRM reveals fix $A B$ mutant bacteroids with a $\mathrm{PHB}^{+}$phenotype show significantly lower levels of polyphosphate, while those with a $\mathrm{PHB}^{-}$phenotype show levels of polyphosphate similar to those in wild-type bacteroids (Fig. 7C).

\section{DISCUSSION}

The fixABCX operon is essential in several nitrogen-fixing bacteria (Gubler and Hennecke 1988; Kaminski et al. 1988). Through a series of deletions with nonpolar and polar effects on downstream genes, we show that the putative operon fixABCXni$f A B$ is essential for nitrogen fixation in $R$. leguminosarum Rlv3841.

The fixA gene is controlled by NifA and is one of the most highly upregulated genes in mature bacteroids across many rhizobial species (Becker et al. 2004; Karunakaran et al. 2009; Peng et al. 2014). Despite having a different organization of genes in the region upstream of fixA, expression of fixA in Rlv3841 and its autoregulation by NifA agrees closely with an earlier study that found a NifA-controlled promoter upstream of fixA in $R$. leguminosarum UPM791 (Martínez et al. 2004). Using a series of cloned putative promoter fragments linked to a Lux reporter, we defined a minimal 175-bp region required for expression of the fix $A B C X$ operon during symbiosis, which contains binding sites for both the transcription factor NifA and its cognate sigma factor RpoN (Fig. 1). There is essentially no expression in free-living bacteria, even at $1 \% \mathrm{O}_{2}$, driven by the region upstream of fixA, although in-planta expression exceeds that of a constitutive neomycin promoter (Fig. 1). Identification of a TSS in Rlv3841 upstream of fixA at $-43 \mathrm{bp}$, used only in bacteroids, confirms the location of $\mathrm{P}_{\text {nifAl }}$ within this fragment (Fig. 1). This TSS is not exactly the same as that described for 
UPM791 (Martínez et al. 2004), as it lies 2 nt further upstream of fixA. Without performing dRNA-seq on both strains with samples prepared in parallel, it is impossible to tell whether this is a difference between the strains or a consequence of the two different techniques used for TSS identification. A second NifAbinding site found farther upstream of $\mathrm{P}_{\text {nifAl }}$ in Rlv3841 is not required for fixA expression and appears to act in a competitive manner. It may be involved in expression of a divergent gene (pRL100201), whose mutation does not alter nitrogen fixation although it is highly up-regulated in bacteroids (Karunakaran et al. 2009).

All six reporter plasmid clones of the fixC-nifA region drive only low levels of expression during symbiosis (Fig. 2), which can be explained by the fact none contain $\mathrm{P}_{\text {nifAl }}$ (Fig. 1, $-43 \mathrm{bp}$ upstream fixA). One of our principal aims in this study was to examine the integrated regulation of the fixABCX and nifA(B) genes in Rlv3841 and to determine whether nifA has a basal promoter independent of $P_{\text {nifAl }}$. This role is served by a FixJdependent promoter in Ensifer meliloti that is absent in R. leguminosarum (David et al. 1988; Ditta et al. 1987). A reporter plasmid containing the last $100 \mathrm{bp}$ of fixX and the fixX-nifA IGR was sufficient for transcription of nifA in free-living bacteria (Fig. 2). TSS mapping shows transcription beginning in the fixX-nifA IGR at -177 bp $\left(\mathrm{P}_{\text {nifA2 }}\right)$ during free-living growth but not during symbiosis (Table 1), agreeing with the reporter fusion results. Analysis of the region upstream of -177 bp shows an RpoD-dependent promoter, although one with poor consensus within the -35 region (Supplementary Fig. S1). This would be consistent with the formation of an unstable RNA polymerase complex and low levels of constitutive gene expression. Reporter expression was also seen in a clone lacking the fixX gene entirely (Fig. 2). This, together with complementation analyses of fixX mutants, provides evidence for a further start site for nifA transcription within fixC. An in-frame deletion of fixX
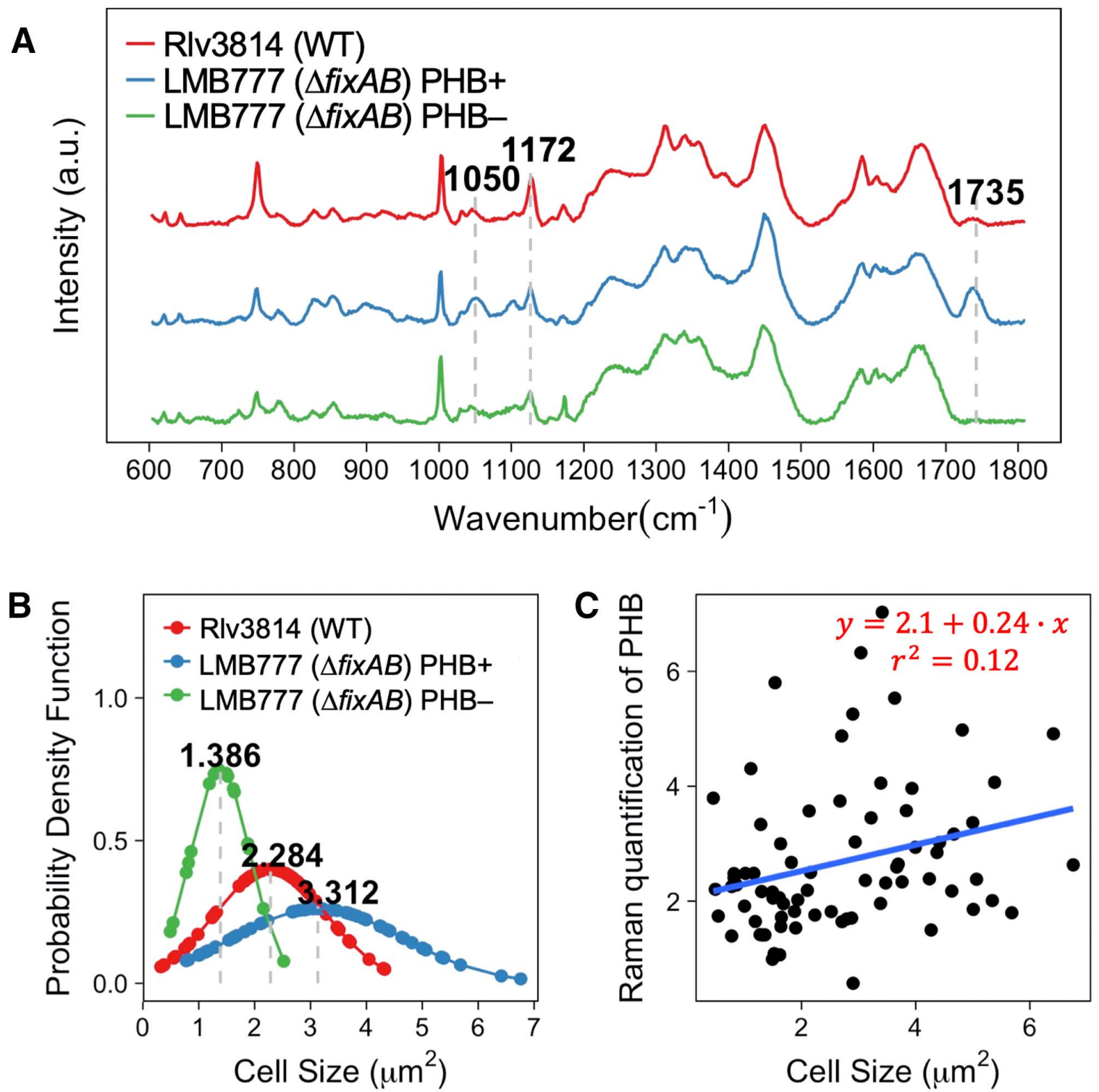

Fig. 6. Comparison of wild-type Rlv3841 and LMB777 bacteroids. A, Averaged single-cell Raman spectrum of bacteroid samples of Rlv3841 (red) and LMB777 $(\triangle$ fix $A B)$, separated by the presence of polyhydroxy-3-butyrate $\left(\mathrm{PHB}^{+}\right.$, blue) or its absence $\left(\mathrm{PHB}^{-}\right.$, green), $n=75$. Peaks at $1,050,1,172$, and $1,735 \mathrm{~cm}^{-1}$ correspond to glycogen, polyphosphate, and PHB, respectively. B, Probability density function for a normal distribution of cell sizes quantified for each individual cell of Rlv3814 (red, $2.284 \mu \mathrm{m}^{2}$ ) and LMB777 $\mathrm{PHB}^{+}$(blue, $3.312 \mu \mathrm{m}^{2}$ ), and LMB777 PHB ${ }^{-}$(green, $1.386 \mu \mathrm{m}^{2}$ ). Mean cell size for each group is given in bold and shows LMB777 $\mathrm{PHB}^{+}$are larger than wild type, while LMB777 $\mathrm{PHB}^{-}$are smaller than wild-type bacteroids. C, Raman quantification of PHB relative to the phenylalanine reference shows there is a proportional relationship between intracellular PHB levels and individual cell size. 
was complemented by fix $X$ alone on a plasmid, while a polar fixX mutation was not. The latter was unable to regain a Fix ${ }^{+}$ phenotype since expression of genes downstream of fix $X$, driven from the $\mathrm{P}_{\text {nifAl }}$ promoter, is interrupted. TSS mapping shows secondary transcription initiation at two sites within fixC, at -757 and $-1,494$ bp (Table 1; Fig. 2). Attempts to complement a polar fixX mutation with plasmids expressing fixXnifA were unsuccessful, suggesting that there is a larger transcriptional unit that also encompasses at least nifB.

Previous studies in $R$. leguminosarum were unable to detect NifA activity under free-living conditions (Martínez et al. 2004). Work in Rhizobium etli detected nifA expression in free-living bacteria under aerobic conditions (Benhassine et al. 2007) and work in Mesorhizobium loti detected expression under microaerobic conditions (Peng et al. 2014). Expression from Rlv3841 PnifA and PfixA promoters was tested in free-living growth under $1 \% \mathrm{O}_{2}$, to determine if gene expression was increased under microaerobic conditions such as those found within nodules. No difference was seen in the expression of either reporter at the two $\mathrm{O}_{2}$ levels, suggesting that control of NifA activity occurs at the posttranscriptional level in Rlv3841. NifA activity has been shown to be oxygen-sensitive in Bradyrhizobium japonicum, and so full NifA activity is likely to be dependent on the extremely low oxygen tensions within nodules (Fischer et al. 1988). Furthermore, there are no obvious anaerobox binding sites for FnrN/FixK upstream of nifA, as there are in Ensifer meliloti, which could induce some level of expression under low oxygen (David et al. 1988; Ditta et al. 1987). Thus, Rlv3841 seems to employ a particularly tight regulation of the entire fix$A B C X n i f A B$ putative operon with minimal constitutive activity from nifA promoters within fixC and the fix-nifA IGR, and with full activation only occurring from $\mathrm{P}_{\text {nifAl }}$ in nodules. Given the conserved NifA-binding sites upstream of the nifHDK operon, this probably also explains the inability to see significant expression of these genes in the laboratory.

Following transcriptional analysis of the fix $A B C X n i f A B$ region, the fix $A B C X$ operon was phenotypically characterized. Whereas the fixABCX operon is not required for growth in freeliving culture, in-frame deletion mutants constructed in fix $A B$, $f i x B, f i x C$, and fix $X$ show a defective symbiotic phenotype lacking detectable nitrogenase activity. The most striking observation was the two different bacteroid morphotypes that were revealed in TEM images of nodules from pea plants inoculated with both the polar and in-frame fixAB mutants (LMB771 and LMB777), remarkable since two different morphotypes of mutant bacteroids have not before been observed in Fix ${ }^{-}$mutant strains. Both phenotypes could be found within a single nodule, though bacteroids were homogenous within individual plant cells. The presence of both morphotypes within a single nodule means that traditional bulk biochemical analysis of fix $A B C X$ mutant nodules would average out the two cell types we have observed, and terminal differentiation of these bacteroids makes their biochemical characterization difficult. As these cells cannot be cultured, large amounts of nodule-derived material from numerous plant experiments would be required to characterize macromolecule levels by traditional means. Additionally, the heterogeneous phenotype detected by electron micrographs makes this identification impossible without cell sorting prior to biochemical assays. Strategies for cell sorting, such as fluorescent labeling, would also require large volumes of bulk material. Using SCRM requires only a small volume of sample and allows analysis without prior labeling, which is particularly beneficial for unculturable samples such as bacteroids. SCRM is a label-free spectroscopic technique that detects the molecular vibrations of all biomolecules in a single cell. Each SCRS can be regarded as a phenotypic profile of a cell, with identifiable Raman bands corresponding to different biomolecules. Given these technological advantages, SCRM was used to characterize levels of PHB, glycogen, and polyphosphate in the heterogeneous population of bacteroids extracted from fixAB mutant nodules.

The first morphotype, seen in all mutant mature nodules investigated, is that of large, swollen bacteroids (designated LARGE) containing granules of PHB clearly visible on electron micrographs. SCRM confirmed that mutant bacteroids that contain more PHB are larger than wild-type bacteroids. Rlv3841 has two genes encoding PHB synthase. The first, phaCl, is found on the chromosome, while the second, phaC2, encoded on pRL10, is expressed specifically in bacteroids (Terpolilli et al. 2016). In Azotobacter spp., PHB has been proposed to play a role in protecting cells from excess reductant under microaerobic conditions (Senior et al. 1972). Removal of this reductant is important, since excess $\mathrm{NAD}(\mathrm{P}) \mathrm{H}$ will inhibit pyruvate
A

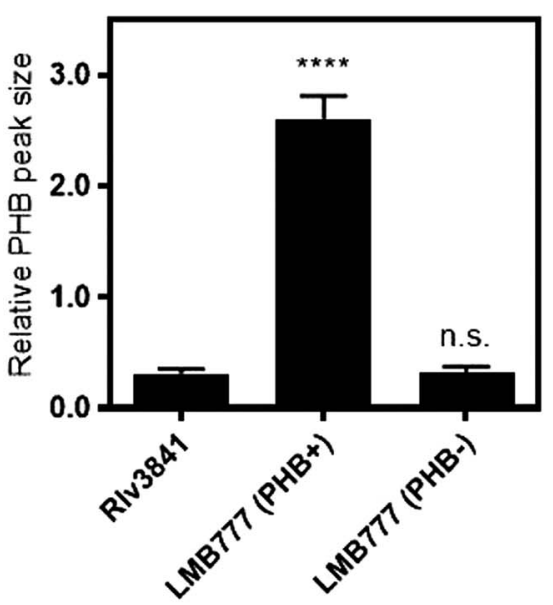

B

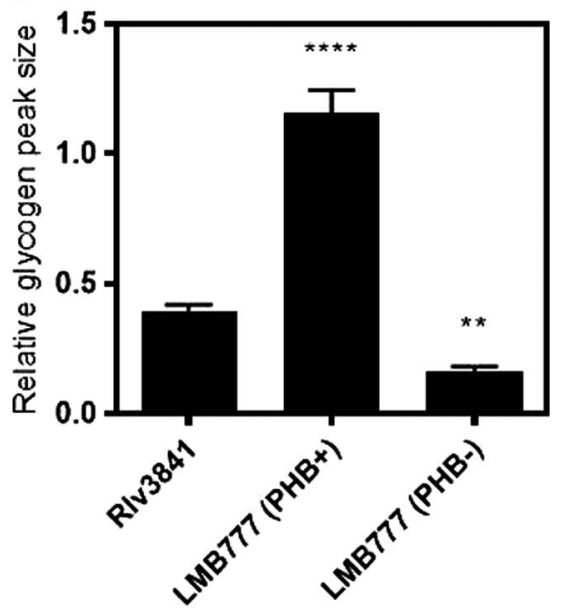

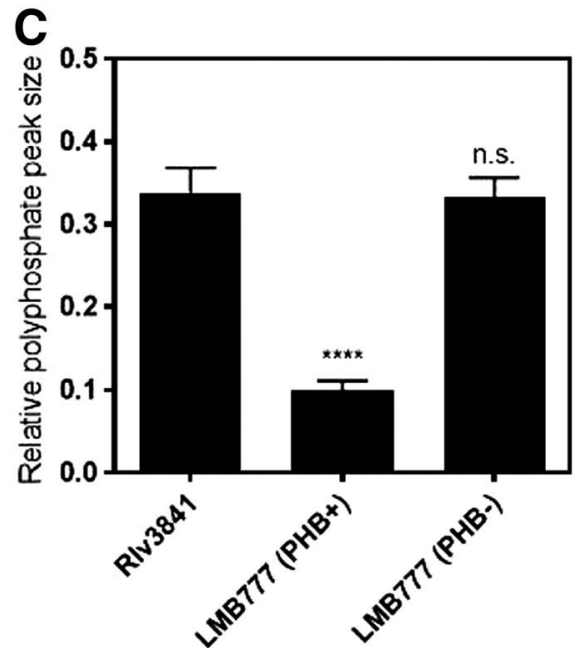

Fig. 7. Comparison of the relative amounts per cell of the storage polymers polyhydroxy-3-butyrate (PHB), glycogen, and polyphosphate in bacteroids of Rlv3841 compared with the two bacteroid morphotypes of LMB777 ( $\triangle$ fixAB), $\mathrm{PHB}^{+}$and $\mathrm{PHB}^{-}$, in pea nodules at 28 days postinoculation. $\mathbf{A}$, Integration of Raman band at $1,735 \mathrm{~cm}^{-1}$ associated with PHB in single-cell Raman spectrum (SCRS) of bacteroids. B, Integration of Raman band at 1,050 $\mathrm{cm}^{-1}$ associated with glycogen in SCRS of bacteroids. C, Integration of Raman band at $1,172 \mathrm{~cm}^{-1}$ associated with polyphosphate in SCRS of bacteroids. In all cases, normalization was against the phenylalanine reference. $n=30$. Statistically distinct groups were determined by two-way analysis of variance and Tukey's multiple comparisons test. Four asterisks $(* * * *)$ indicate $P<0.0001$, two $(* *) P<0.01$, and n. s. $=$ not significant. 
dehydrogenase, a key enzyme in symbiotic nitrogen fixation as well as tricarboxylic acid (TCA) cycle enzymes such as isocitrate dehydrogenase and $\alpha$-ketoglutarate dehydrogenase (Pettit et al. 1975; Salminen and Streeter 1990). Since FixABCX donates electrons to nitrogenase, the absence of FixAB leads to an excess of reduced nucleotides in bacteroids.

While LARGE/PHB ${ }^{+}$fixAB mutant bacteroids contain an order of magnitude more PHB, they also accumulate glycogen. This coupled PHB-glycogen phenotype was recognized before in $R$. leguminosarum bv. viciae $\mathrm{A} 34$, in which a phaC mutant had 4.5-fold less glycogen than wild type (Lodwig et al. 2005). The link between these two carbon storage molecules suggests a global carbon regulatory system in $R$. leguminosarum bv. viciae (Sánchez-Cañizares et al. 2020). Polyphosphate was also measured in both bacteroid morphotypes, showing reduced levels in the LARGE/PHB ${ }^{+}$morphotype and wild-type levels in the SMALL/PHB ${ }^{-}$morphotype (Fig. 7).

Although the second bacteroid morphotype, SMALL/PHB ${ }^{-}$ bacteroids, resemble bacterial cells in infection threads in size, they lack PHB, unlike infection-thread cells, which have high levels of this polymer (Lodwig et al. 2005). This may indicate that SMALL/PHB ${ }^{-}$bacteroids have used up existing stores of PHB (produced by PhaC1) to fuel the TCA cycle in the absence of plant-derived carbon. These smaller cells also contain dark electron-dense polar inclusions, which were not conclusively identified. Quantification of polyphosphate by SCRM showed that the level of polyphosphate in SMALL/PHB ${ }^{-}$mutant bacteroids is approximately the same as those of wild type (Fig. 7), but, given their smaller size, we speculate that the higher concentration of polyphosphate might give rise to granules visible in TEM images.

Analysis of bacteroid morphology in TEM images has shown that there is a tight relationship between nitrogen fixation and the occurrence of storage polymers. In addition to PHB, other storage polymers have been identified as playing a role in nitrogen fixation in R. leguminosarum bv. viciae, including glycogen (Lodwig et al. 2005) and lipids (Terpolilli et al. 2016). In symbiosis, a careful balance is required to ensure that the bacteroid does not experience detrimental redox stress during nitrogen fixation. The combination of electron microscopy and SCRM has revealed details of a previously unknown phenomenon in nonfixing rhizobia. A lack of fixed nitrogen provided to the plant can affect nodule development (Westhoek et al. 2017) and the heterogeneity observed between isogenic bacteroids within different plant cells of mature nodules may result from a perturbation of signals between the plant host and fixAB mutant bacteroids.

Overall, we show that $R$. leguminosarum maintains a very tight autoregulation of the putative fixABCXnifAB operon through a series of sites for initiation of transcription mapped under different developmental conditions. Autoregulation by NifA presumably prevents any significant expression until the extremely low $\mathrm{O}_{2}$ tensions of the nodule are encountered. Through observations from TEM images and SCRM chemical characterization of the two mutant morphotypes of fix $A B$ bacteroids, we have seen differences in storage polymer accumulation and suggest that they play a role in maintaining efficient and robust nitrogen fixation in wild-type rhizobia.

\section{MATERIALS AND METHODS}

\section{Bacterial strains.}

All bacterial strains, plasmids, and primers used in this study are listed in Supplementary Table S1.

\section{Media and bacterial growth conditions.}

$R$. leguminosarum strains were grown at $28^{\circ} \mathrm{C}$ in $\mathrm{TY}$ broth and solid medium with streptomycin $(250 \mu \mathrm{g} / \mathrm{ml})$. E. coli strains were grown at $37^{\circ} \mathrm{C}$ in lysogeny broth (LB) medium. Media were supplemented with antibiotics as required: ampicillin (100 $\mu \mathrm{g} / \mathrm{ml})$, streptomycin $(250 \mu \mathrm{g} / \mathrm{ml})$, spectinomycin $(100 \mu \mathrm{g} / \mathrm{ml})$, kanamycin $(50 \mu \mathrm{g} / \mathrm{ml})$, neomycin $(80 \mu \mathrm{g} / \mathrm{ml})$, and tetracycline ( $5 \mu \mathrm{g} / \mathrm{ml}$ for R. leguminosarum and $10 \mu \mathrm{g} / \mathrm{ml}$ for E. coli).

\section{Reporter fusions and luminescence assays.}

Plasmids to assess promoter activity in $R$. leguminosarum were constructed by cloning fragments upstream of the promoterless luxABCDE cluster in plasmid pIJ11268 (Frederix et al. 2014) and measuring luminescence under different conditions. DNA fragments containing potential promoters were PCRamplified, using primers listed in Table 2. PCR was performed using Phusion high-fidelity DNA polymerase (Thermo Fisher), according to manufacturer instructions, using the following program: $30 \mathrm{~s}$ at $98^{\circ} \mathrm{C}$ followed by 35 cycles of $98^{\circ} \mathrm{C}$ for $15 \mathrm{~s}$, $68^{\circ} \mathrm{C}$ for $30 \mathrm{~s}, 72^{\circ} \mathrm{C}$ for $15 \mathrm{~s}$ per kilobase of expected product, heated to $72^{\circ} \mathrm{C}$ for $5 \mathrm{~min}$, before being held at $4^{\circ} \mathrm{C}$. PCR products were cloned into KpnI/BamHI- (NEB) digested pIJ11268. Constructs were confirmed by PCR-sequencing with pIJ11268for and pIJ11268rev primers (Eurofins, MWG Operon). Triparental conjugation was used to transfer plasmids from $E$. coli to $R$. leguminosarum, as previously described, and transconjugants were selected on tetracycline (Poole et al. 1994). Lux and $\mathrm{OD}_{595}$ measurements of free-living cells were made using a FLUOstar Omega plate reader (BMG Labtech). To compare the effect of $\mathrm{O}_{2}$ on reporter gene expression, cultures (three biological replicates, in triplicate) were grown at $28^{\circ} \mathrm{C}, 500 \mathrm{rpm}$, following inoculation with $5 \times 10^{7}$ bacterial cells at 1 or $21 \% \mathrm{O}_{2}$ in a FLUOstar Omega plate reader. Luminescence in pea root nodules was recorded using a NightOWL LB 983 Imaging System (Berthold Technologies).

\section{5 '-end mapping of TSSs.}

Bacteroid samples were prepared as previously described (Rutten et al. 2021) Free-living samples were grown in liquid culture under the following conditions: TY, acid minimal salts (AMS) (Poole et al. 1994) $20 \mathrm{mM}$ succinate $10 \mathrm{mM}$ ammonia, AMS $10 \mathrm{mM}$ glucose $10 \mathrm{mM}$ ammonia, AMS $10 \mathrm{mM}$ mannitol $10 \mathrm{mM}$ ammonia, AMS $30 \mathrm{mM}$ pyruvate $10 \mathrm{mM}$ ammonia, AMS $10 \mathrm{mM}$ arabinose $10 \mathrm{mM}$ ammonia, AMS $10 \mathrm{mM}$ inositol $10 \mathrm{mM}$ ammonia, AMS $3 \mathrm{mM}$ protocatechuate $10 \mathrm{mM}$ ammonia, AMS $3 \mathrm{mM}$ catechol $10 \mathrm{mM}$ ammonia, AMS $10 \mathrm{mM}$ glucose $5 \mathrm{mM}$ phenylalanine $5 \mathrm{mM}$ ammonia, AMS $10 \mathrm{mM}$ glucose $10 \mathrm{mM}$ ammonia, $\mathrm{pH}$ 5.75, AMS $10 \mathrm{mM}$ glucose $10 \mathrm{mM}$ ammonia grown in steady state at $0.1 \% \mathrm{O}_{2}$, AMS $10 \mathrm{mM}$ glucose $10 \mathrm{mM}$ ammonia $100 \mathrm{mM} \mathrm{NaCl}$, AMS $10 \mathrm{mM}$ glucose $10 \mathrm{mM}$ ammonia $100 \mathrm{mM} \mathrm{H}_{2} \mathrm{O}_{2}$ and prepared as described by Rutten et al. (2021).

Library preparation, sequencing, and subsequent analysis using TSSer (Jorjani and Zavolan 2014) and TSSAR (Amman et al. 2014) was as described by Rutten et al. (2021). Sequence logos of potential promoters were created in Weblogo (Crooks et al. 2004). The complete raw dataset has been submitted to the Short Read Archive database and given the BioProject accession number PRJNA667846.

\section{Isolation of fix $A B C X$ mutants.}

All mutants were constructed in strain Rlv3841 and the steps are summarized in Supplementary Figure S2. To make fix $A B$ mutants, the fixAB genes together with $1-\mathrm{kb} 5^{\prime}$ - and $3^{\prime}$-flanking regions were PCR-amplified using primer pair pr1450/pr1451 (adding an XbaI site at the $3^{\prime}$ end and a BamHI site at the 5' end). This PCR product was ligated into pJET1.2/blunt (Clontech), using T4 DNA ligase according to manufacturer protocol (Thermo Fisher), to give plasmid pLMB721. To create deletions in this fragment, inverse PCR (with primer pair pr1622/pr1623) 
was used with pLMB721 as a template to delete 1,921 bp and insert an EcoRI site. Following digestion of the PCR product with EcoRI and ligation (forming plasmid pLMB814), the $E c o$ RI site was used to insert an $\Omega$ Spec cassette (to give pLMB815). Plasmid pLMB815 was then digested with XbaI amd BamHI and the fragment was cloned into pJQ200SK (cut with the same enzyme) to construct plasmid pLMB818 ( $\Omega$ Spec cassette together with fixA and fixB flanking DNA) in E. coli before conjugation into Rlv3841. Triparental filter conjugation was performed, selecting spectinomycin-resistant colonies with subsequent sucrose selection (which leads to the loss of plasmid pJQ200SK as it is no longer maintained when sucrose is present in the media) (Quandt and Hynes 1993), to give mutant strain

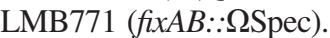

Mutant strain LMB777 ( $\triangle$ fixAB) was made by cloning $X b a \mathrm{I}-$ and BamHI-digested pLMB814 into pJQ200SK (making pLMB818), followed by conjugation (as described previously) into LMB771, selecting for loss of spectinomycin resistance. The same protocol was used to make fixC and fixX mutants, using primers listed in Supplementary Table S1 to make strains

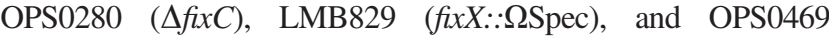
$(\triangle f i x X)$. All mutants were confirmed by mapping PCR and sequencing.

\section{Mutant complementation.}

Experiments to complement $\mathrm{Fix}^{-}$mutations were performed using genes cloned in vector pJP2 (Prell et al. 2002). DNA fragments were PCR-amplified, fix $A B$ with primer pair pr1485/ pr1486 and fixABCX with pr1620/pr1621, were digested with $\mathrm{XbaI}$ and $\mathrm{BamHI}$, and were cloned to make plasmids pLMB811 and pLMB826, respectively (Supplementary Table S1).

Since conventional cloning of the region upstream of nifA proved difficult due to the presence of restriction enzymes sites, Golden Gate cloning was used instead. Vector backbone pOGG026, a minimal pJP2 variant encoding resistance to neomycin, developed for Golden Gate (Geddes et al. 2019), was used to construct pOPS0303 from the $\mathrm{P}_{\text {nifal }}$ promoter (PCR product oxp0822/oxp0823 with Rlv3841 as template, cloned to give pOGG095), fixXnifA, and the Pharmacia terminator. Golden Gate reactions were carried out using $1 \mu \mathrm{l}$ of BsaI, $1 \mu \mathrm{l}$ of T4 DNA ligase, $1.5 \mu \mathrm{l}$ of DNA ligase buffer (Thermo Scientific), $1.5 \mu \mathrm{l}$ of bovine serum albumin $(2 \mathrm{mg} / \mathrm{ml})$, and $40 \mathrm{fmol}$, each, of promoter, gene, terminator, and backbone, made up to 15 $\mu \mathrm{l}$ with $\mathrm{H}_{2} \mathrm{O}$. For pOPS0303 these were: promoter (pOGG095), gene (PCR product amplified with primer pair oxp0801/ oxp0808 from pOPS0302 as template), terminator (pOGG003), and backbone (pOGG026) (Supplementary Table S1).

Plasmids were conjugated into mutant strains using triparental mating with helper plasmid pRK2013 (Ditta et al. 1980) and selecting for resistance to tetracycline (pLMB811 and pLMB826) or neomycin (pOPS0303).

\section{Plant growth and inoculation.}

$P$. sativum (cv. Avola) seeds were sterilized with a 1-min incubation in $70 \%$ ethanol and a 5 -min incubation in $2 \%$ sodium hypochlorite, followed by six repeated washes in sterile distilled $\mathrm{H}_{2} \mathrm{O}\left(\mathrm{dH}_{2} \mathrm{O}\right)$. Sterilized seeds were planted in 1-1 pots containing autoclaved vermiculite and $400 \mathrm{ml}$ of nitrogen-free nutrient solution (Beringer 1974). Seeds were inoculated on the day of planting with $1 \mathrm{ml}$ of culture containing $10^{7}$ colony-forming units. Plants were grown at $22^{\circ} \mathrm{C}$ on a 16-h-light and 8-h-dark cycle. Plants were harvested and acetylene reduction was assayed at 28 dpi. Harvested nodules were crushed using a pestle and mor-

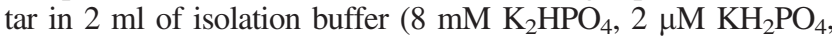
$30 \mathrm{mM}$ sucrose, $2 \mathrm{mM} \mathrm{MgCl} 2$ made up in sterile $\mathrm{dH}_{2} \mathrm{O}$ ) per gram of nodules and the resulting brei filtered through two layers of muslin. Brei was centrifuged at $120 \times g$ for 5 min to pellet heavier plant material. The supernatant from this spin was then centrifuged at $4,300 \times g$ for 5 min to pellet bacteroids.

\section{Acetylene reduction assay for nitrogenase activity.}

Plants were harvested from vermiculite at $28 \mathrm{dpi}$ and were placed in 250-ml Schott bottles with injectable seals. We removed $2 \%$ of the air from each bottle and replaced it with acetylene. Plants were incubated with acetylene for $1 \mathrm{~h}$ before $1-\mathrm{ml}$ samples were removed. Conversion of acetylene to ethylene was measured using gas chromatography (Perkin-Elmer GC). Variation in acetylene reduction rates between assays reflect differences in plant growth conditions at the John Innes Centre (where this work was begun) and the University of Oxford (where this work was concluded). Despite identical light and dark cycles, there are inevitably differences in the amount and nature of light received by the plants in the constant temperature growth rooms at the two establishments.

\section{Microscopy and ultrastructural analysis.}

Nodules (three per plant, from three pea plants) were fixed in a solution of $2.5 \%$ ( $\mathrm{vol} / \mathrm{vol}$ ) glutaraldehyde in $0.05 \mathrm{M}$ sodium cacodylate $(\mathrm{pH} 7.3)$. Samples were washed in $0.05 \mathrm{M}$ sodium cacodylate and were postfixed with $1 \%$ (wt/vol) $\mathrm{OsO}_{4}$ in 0.05 $\mathrm{M}$ sodium cacodylate for $60 \mathrm{~min}$ at room temperature (Lodwig et al. 2005). Samples were then washed and dehydrated with ethanol before gradual infiltration with LR white resin (London Resin Company) according to manufacturer protocol. Nodules were then sectioned, using a Leica UC6 ultramicrotome (Leica), through the nitrogen-fixing zone or the widest part of the nodule (if spherical). Ultrathin sections of $90 \mathrm{~nm}$ (up to three per nodule) were picked up on 200-mesh hold grids coated in pyroxylin and carbon. Grids were viewed on a FEI Tecnai 20 transmission electron microscope at 2,000 kV. Digital images were taken using an AMT XR60B digital camera (Deben). Bacteroid sizes were determined using ImageJ software (National Institutes of Health $[\mathrm{NIH}])$. Bacteroid area was measured for 100 bacteroids per strain or cell type, from a total of up to 27 images (up to three sections of three nodules taken from three plants). These were selected at random following initial identification, by eye, of infection thread and bacteroid cells and quantifying the size of these cells separately from each other (Supplementary Fig. S10).

\section{SCRM measurements and analysis.}

Cell pellets were washed three times with $\mathrm{dH}_{2} \mathrm{O}$ to remove traces of media and diluted to about 1,000 cells per milliliter. Cell suspensions were spread onto an aluminum-coated slide and were observed under a $100 \times / 0.9$ microscope objective. SCRS were acquired using a HR Evolution confocal Raman microscope (Horiba) equipped with a 532-nm neodymiumyttrium aluminum garnet laser and 600 grooves per millimeter diffraction grating. The laser power was attenuated to $4.7 \mathrm{~mW}$ using neutral density filters. Spectra were acquired in the range of 600 to $1,900 \mathrm{~cm}^{-1}$ by exposing single cells to a $1-\mu \mathrm{m}$ laser spot for $20 \mathrm{~s}$. For each sample, 30 to 50 single cells were analyzed. All spectra were preprocessed by baseline correction, using LabSpec 6 (Horiba Scientific). Spectral normalization was done by vector normalization of the entire spectral region. Data analysis, statistics, and visualization were done under an R environment, using in-house scripts. Bacterial sizes were determined using ImageJ (NIH). Quantification of intracellular biomolecules using SCRS was done by integrating corresponding Raman bands that were then normalized against the integration of a reference phenylalanine band centered at $1,003 \mathrm{~cm}^{-1}$.

\section{Statistical analysis.}

Data analysis was carried out using GraphPad Prism 8 (GraphPad Software). Significant differences between pairs of 
parameters were determined by Student's $t$ tests. Comparisons of more than two groups were done by analysis of variance followed by multiple comparison post hoc corrections as indicated in each figure legend. A $P$ value of less than 0.05 was considered statistically significant.

\section{ACKNOWLEDGMENTS}

We thank E. Barclay (John Innes Centre) for help with bioimaging.

\section{AUTHOR-RECOMMENDED INTERNET RESOURCE}

Weblogo: https://weblogo.berkeley.edu

\section{LITERATURE CITED}

Agron, P. G., Ditta, G. S., and Helinski, D. R. 1992. Mutational analysis of the Rhizobium meliloti nifA promoter. J. Bacteriol. 174:4120-4129.

Amman, F., Wolfinger, M. T., Lorenz, R., Hofacker, I. L., Stadler, P. F., and Findeiß, S. 2014. TSSAR: TSS annotation regime for dRNA-seq data. BMC Bioinformatics 15:89.

Arigoni, F., Kaminski, P. A., Hennecke, H., and Elmerich, C. 1991. Nucleotide sequence of the fix $A B C$ region of Azorhizobium caulinodans ORS571: Similarity of the fixB product with eukaryotic flavoproteins, characterization of fixX, and identification of nifW. Mol. Gen. Genet. 225:514-520.

Barnett, M. J., Toman, C. J., Fisher, R. F., and Long, S. R. 2004. A dualgenome symbiosis chip for coordinate study of signal exchange and development in a prokaryote-host interaction. Proc. Natl. Acad. Sci. U.S.A. 101:16636-16641.

Batut, J., Terzaghi, B., Gherardi, M., Huguet, M., Terzaghi, E., Garnerone, A. M., Boistard, P., and Huguet, T. 1985. Localization of a symbiotic fix region on Rhizobium meliloti psym megaplasmid more than 200 kilobases from the nod-nif region. Mol. Gen. Genet. 199:232239.

Bauer, E., Kaspar, T., Fischer, H. M., and Hennecke, H. 1998. Expression of the fixR-nifA operon in Bradyrhizobium japonicum depends on a new response regulator, RegR. J. Bacteriol. 180:3853-3863.

Becker, A., Bergès, H., Krol, E., Bruand, C., Rüberg, S., Capela, D., Lauber, E., Meilhoc, E., Ampe, F., de Bruijn, F. J., Fourment, J., Francez-Charlot, A., Kahn, D., Küster, H., Liebe, C., Pühler, A., Weidner, S., and Batut, J. 2004. Global changes in gene expression in Sinorhizobium meliloti 1021 under microoxic and symbiotic conditions. Mol. Plant-Microbe Interact. 17:292-303.

Benhassine, T., Fauvart, M., Vanderleyden, J., and Michiels, J. 2007. Interaction of an IHF-like protein with the Rhizobium etli nifA promoter. FEMS Microbiol. Lett. 271:20-26.

Beringer, J. E. 1974. R factor transfer in Rhizobium leguminosarum. J. Gen. Microbiol. 84:188-198.

Bode, G., Mauch, F., Ditschuneit, H., and Malfertheiner, P. 1993. Identification of structures containing polyphosphate in Helicobacter pylori. J. Gen. Microbiol. 139:3029-3033.

Brito, B., Martínez, M., Fernández, D., Rey, L., Cabrera, E., Palacios, J. M., Imperial, J., and Ruiz-Argüeso, T. 1997. Hydrogenase genes from Rhizobium leguminosarum bv. viciae are controlled by the nitrogen fixation regulatory protein nifA. Proc. Natl. Acad. Sci. U.S.A. 94: 6019-6024.

Burén, S., Jiang, X., López-Torrejón, G., Echavarri-Erasun, C., and Rubio, L. M. 2017. Purification and in vitro activity of mitochondria targeted nitrogenase cofactor maturase NifB. Front. Plant Sci. 8:1567.

Craig, A. S., and Williamson, K. I. 1972. Three inclusions of rhizobial bacteroids and their cytochemical character. Arch. Microbiol. 87:165171

Crooks, G. E., Hon, G., Chandonia, J. M., and Brenner, S. E. 2004. WebLogo: A sequence logo generator. Genome Res. 14:1188-1190.

David, M., Daveran, M. L., Batut, J., Dedieu, A., Domergue, O., Ghai, J., Hertig, C., Boistard, P., and Kahn, D. 1988. Cascade regulation of nif gene expression in Rhizobium meliloti. Cell 54:671-683.

Ditta, G., Stanfield, S., Corbin, D., and Helinski, D. R. 1980. Broad host range DNA cloning system for gram-negative bacteria: Construction of a gene bank of Rhizobium meliloti. Proc. Natl. Acad. Sci. U.S.A. 77:7347-7351.

Ditta, G., Virts, E., Palomares, A., and Kim, C. H. 1987. The nifA gene of Rhizobium meliloti is oxygen regulated. J. Bacteriol. 169:32173223 .
Dusha, I., Kovalenko, S., Banfalvi, Z., and Kondorosi, A. 1987. Rhizobium meliloti insertion element ISRm2 and its use for identification of the fixX gene. J. Bacteriol. 169:1403-1409.

Earl, C. D., Ronson, C. W., and Ausubel, F. M. 1987. Genetic and structural analysis of the Rhizobium meliloti fixA, fixB, fixC, and fixX genes. J. Bacteriol. 169:1127-1136.

Edgren, T., and Nordlund, S. 2006. Two pathways of electron transport to nitrogenase in Rhodospirillum rubrum: The major pathway is dependent on the fix gene products. FEMS Microbiol. Lett. 260:30-35.

Ferrières, L., and Kahn, D. 2002. Two distinct classes of FixJ binding sites defined by in vitro selection. FEBS Lett. 517:185-189.

Finan, T. M. 2002. Evolving insights: Symbiosis islands and horizontal gene transfer. J. Bacteriol. 184:2855-2856.

Fischer, H.-M., Alvarez-Morales, A., and Hennecke, H. 1986. The pleiotropic nature of symbiotic regulatory mutants: Bradyrhizobium japonicum nifA gene is involved in control of nif gene expression and formation of determinate symbiosis. EMBO J. 5:1165-1173.

Fischer, H. M., Bruderer, T., and Hennecke, H. 1988. Essential and nonessential domains in the Bradyrhizobium japonicum NifA protein: Identification of indispensable cysteine residues potentially involved in redox reactivity and/or metal binding. Nucleic Acids Res. 16:22072224

Frederix, M., Edwards, A., Swiderska, A., Stanger, A., Karunakaran, R., Williams, A., Abbruscato, P., Sanchez-Contreras, M., Poole, P. S., and Downie, J. A. 2014. Mutation of praR in Rhizobium leguminosarum enhances root biofilms, improving nodulation competitiveness by increased expression of attachment proteins. Mol. Microbiol. 93:464478.

Friedberg, I., and Avigad, G. 1968. Structures containing polyphosphate in Micrococcus lysodeikticus. J. Bacteriol. 96:544-553.

Garcia Costas, A. M., Poudel, S., Miller, A.-F., Schut, G. J., Ledbetter, R. N., Fixen, K. R., Seefeldt, L. C., Adams, M. W. W., Harwood, C. S., Boyd, E. S., and Peters, J. W. 2017. Defining electron bifurcation in the electron-transferring flavoprotein family. J. Bacteriol. 199: e00440-17.

Geddes, B. A., Mendoza-Suárez, M. A., and Poole, P. S. 2019. A Bacterial Expression Vector Archive (BEVA) for Flexible Modular Assembly of Golden Gate-Compatible Vectors. Front. Microbiol. 9:3345.

Gubler, M., and Hennecke, H. 1988. Regulation of the fixA gene and fixBC operon in Bradyrhizobium japonicum. J. Bacteriol. 170:12051214

Gubler, M., Zürcher, T., and Hennecke, H. 1989. The Bradyrhizobium japonicum fixBCX operon: Identification of fixX and of a $5^{\prime}$ mRNA region affecting the level of the fixBCX transcript. Mol. Microbiol. 3: 141-148.

Gutiérrez, D., Hernando, Y., Palacios, J. M., Imperial, J., and RuizArgüeso, T. 1997. FnrN controls symbiotic nitrogen fixation and hydrogenase activities in Rhizobium leguminosarum biovar viciae UPM791. J. Bacteriol. 179:5264-5270.

Heinrich, K., Ryder, M.H., and Murphy, P.J. 2001. Early production of rhizopine in nodules induced by Sinorhizobium meliloti strain L5-30. Can. J. Microbiol. 47:165-171.

Hirsch, A. M., and Smith, C. A. 1987. Effects of Rhizobium meliloti nif and fix mutants on alfalfa root nodule development. J. Bacteriol. 169: $1137-1146$

Jorjani, H., and Zavolan, M. 2014. TSSer: An automated method to identify transcription start sites in prokaryotic genomes from differential RNA sequencing data. Bioinformatics 30:971-974.

Kaminski, P.A., Norel, F., Desnoues, N., Kush, A., Salzano, G., and Elmerich, C. 1988. Characterization of the fix $A B C$ region of Azorhizobium caulinodans ORS571 and identification of a new nitrogen fixation gene. Mol. Gen. Genet. 214:496-502.

Karunakaran, R., Ramachandran, V. K., Seaman, J. C., East, A. K., Mouhsine, B., Mauchline, T. H., Prell, J., Skeffington, A., and Poole, P. S. 2009. Transcriptomic analysis of Rhizobium leguminosarum biovar viciae in symbiosis with host plants Pisum sativum and Vicia cracca. J. Bacteriol. 191:4002-4014.

Kües, U., and Stahl, U. 1989. Replication of plasmids in gram-negative bacteria. Microbiol. Rev. 53:491-516.

Labes, M., Rastogi, V., Watson, R., and Finan, T. M. 1993. Symbiotic nitrogen fixation by a nifA deletion mutant of Rhizobium meliloti: The role of an unusual $n t r C$ allele. J. Bacteriol. 175:2662-2673.

Ledbetter, R. N., Garcia Costas, A. M., Lubner, C. E., Mulder, D. W., Tokmina-Lukaszewska, M., Artz, J. H., Patterson, A., Magnuson, T. S., Jay, Z. J., Duan, H. D., Miller, J., Plunkett, M. H., Hoben, J. P., Barney, B. M., Carlson, R. P., Miller, A.-F., Bothner, B., King, P. W., Peters J. W., and Seefeldt, L. C. 2017. The electron bifurcating FixABCX protein complex from Azotobacter vinelandii: Generation of low-potential 
reducing equivalents for nitrogenase catalysis. Biochemistry 56:41774190 .

Lindemann, A., Moser, A., Pessi, G., Hauser, F., Friberg, M., Hennecke, H., and Fischer, H. M. 2007. New target genes controlled by the Bradyrhizobium japonicum two-component regulatory system RegSR. J. Bacteriol. 189:8928-8943.

Lodwig, E. M., Leonard, M., Marroqui, S., Wheeler, T. R., Findlay, K., Downie, J. A., and Poole, P. S. 2005. Role of polyhydroxybutyrate and glycogen as carbon storage compounds in pea and bean bacteroids. Mol. Plant-Microbe Interact. 18:67-74.

Lubner, C. E., Jennings, D. P., Mulder, D. W., Schut, G. J., Zadvornyy, O. A., Hoben, J. P., Tokmina-Lukaszewska, M., Berry, L., Nguyen, D. M., Lipscomb, G. L., Bothner, B., Jones, A. K., Miller, A. F., King, P. W., Adams, M. W. W., and Peters, J. W. 2017. Mechanistic insights into energy conservation by flavin-based electron bifurcation. Nat. Chem. Biol. 13:655-659.

Martínez, M., Palacios, J. M., Imperial, J., and Ruiz-Argüeso, T. 2004. Symbiotic autoregulation of nifA expression in Rhizobium leguminosarum bv. viciae. J. Bacteriol. 186:6586-6594.

Mergaert, P., Uchiumi, T., Alunni, B., Evanno, G., Cheron, A., Catrice, O., Mausset, A.-E., Barloy-Hubler, F., Galibert, F., Kondorosi, A., and Kondorosi, E. 2006. Eukaryotic control on bacterial cell cycle and differentiation in the Rhizobium-legume symbiosis. Proc. Natl. Acad. Sci. U.S.A. 103:5230-5235.

Ott, T., van Dongen, J. T., Günther, C., Krusell, L., Desbrosses, G., Vigeolas, H., Bock, V., Czechowski, T., Geigenberger, P., and Udvardi, M. K. 2005. Symbiotic leghemoglobins are crucial for nitrogen fixation in legume root nodules but not for general plant growth and development. Curr. Biol. 15:531-535.

Pallerla, S. R., Knebel, S., Polen, T., Klauth, P., Hollender, J., Wendisch, V. F., and Schoberth, S. M. 2005. Formation of volutin granules in Corynebacterium glutamicum. FEMS Microbiol. Lett. 243:133-140.

Peng, J., Hao, B., Liu, L., Wang, S., Ma, B., Yang, Y., Xie, F., and Li, Y. 2014. RNA-Seq and microarrays analyses reveal global differential transcriptomes of Mesorhizobium huakuii 7653R between bacteroids and free-living cells. PLoS One 9:e93626.

Pettit, F. H., Pelley, J. W., and Reed, L. J. 1975. Regulation of pyruvate dehydrogenase kinase and phosphatase by acetyl-CoA/CoA and NADH/NAD ratios. Biochem. Biophys. Res. Commun. 65:575-582.

Poole, P., Ramachandran, V., and Terpolilli, J. 2018. Rhizobia: From saprophytes to endosymbionts. Nat. Rev. Microbiol. 16:291-303.

Poole, P. S., Blyth, A., Reid, C. J., and Walters, K. 1994. myo-Inositol catabolism and catabolite regulation in Rhizobium leguminosarum bv viciae. Microbiology 140:2787-2795.

Poudel, S., Colman, D. R., Fixen, K. R., Ledbetter, R. N., Zheng, Y., Pence, N., Seefeldt, L. C., Peters, J. W., Harwood, C. S., and Boyd, E. S. 2018. Electron transfer to nitrogenase in different genomic and metabolic backgrounds. J. Bacteriol. 200:e00757-00717.

Prell, J., Boesten, B., Poole, P., and Priefer, U. B. 2002. The Rhizobium leguminosarum bv. viciae VF39 $\gamma$-aminobutyrate (GABA) aminotransferase gene $(g a b T)$ is induced by GABA and highly expressed in bacteroids. Microbiol. Read. 148:615-623.

Quandt, J., and Hynes, M. F. 1993. Versatile suicide vectors which allow direct selection for gene replacement in gram-negative bacteria. Gene 127:15-21.
Rutten, P. J., and Poole, P. S. 2019. Chapter Nine - Oxygen regulatory mechanisms of nitrogen fixation in rhizobia. Pages 325-389 in: Advances in Microbial Physiology. R. K. Poole, ed. Academic Press, New York.

Rutten, P. J., Steel, H., Hood, G. A., Ramachandran, V. K., McMurtry, L., Geddes, B., Papachristodoulou, A., and Poole, P. S. 2021. Multiple sensors provide spatiotemporal oxygen regulation of gene expression in a Rhizobium-legume symbiosis. PLoS Genet. 17:e1009099.

Salazar, E., Díaz-Mejía, J. J., Moreno-Hagelsieb, G., Martínez-Batallar, G., Mora, Y., Mora, J., and Encarnación, S. 2010. Characterization of the NifA-RpoN regulon in Rhizobium etli in free life and in symbiosis with Phaseolus vulgaris. Appl. Environ. Microbiol. 76:4510-4520.

Salminen, S. O., and Streeter, J. G. 1990. Factors contributing to the accumulation of glutamate in Bradyrhizobium japonicum bacteroids under microaerobic conditions. J. Gen. Microbiol. 136:2119-2126.

Sánchez-Cañizares, C., Prell, J., Pini, F., Rutten, P., Kraxner, K., Wynands, B., Karunakaran, R., and Poole, P. S. 2020. Global control of bacterial nitrogen and carbon metabolism by a $\mathrm{PTS}^{\mathrm{Ntr}}$-regulated switch. Proc. Natl. Acad. Sci. U.S.A. 117:10234-10245.

Senior, P. J., Beech, G. A., Ritchie, G. A. F., and Dawes, E. A. 1972. The role of oxygen limitation in the formation of poly- $\beta$-hydroxybutyrate during batch and continuous culture of Azotobacter beijerinckii. Biochem. J. 128:1193-1201.

Sullivan, J. T., Brown, S. D., and Ronson, C. W. 2013. The NifA-RpoN regulon of Mesorhizobium loti strain R7A and its symbiotic activation by a novel LacI/GalR-family regulator. PLoS One 8:e53762.

Terpolilli, J. J., Masakapalli, S. K., Karunakaran, R., Webb, I. U. C., Green, R., Watmough, N. J., Kruger, N. J., Ratcliffe, R. G., and Poole, P. S. 2016. Lipogenesis and redox balance in nitrogen-fixing pea bacteroids. J. Bacteriol. 198:2864-2875.

Tsai, M. H., and Saier, M. H., Jr. 1995. Phylogenetic characterization of the ubiquitous electron transfer flavoprotein families ETF- $\alpha$ and ETFB. Res. Microbiol. 146:397-404.

Tsukada, S., Aono, T., Akiba, N., Lee, K.-B., Liu, C.-T., Toyazaki, H., and Oyaizu, H. 2009. Comparative genome-wide transcriptional profiling of Azorhizobium caulinodans ORS571 grown under free-living and symbiotic conditions. Appl. Environ. Microbiol. 75:5037-5046.

Udvardi, M., and Poole, P. S. 2013. Transport and metabolism in legume-rhizobia symbioses. Annu. Rev. Plant Biol. 64:781-805.

Watmough, N. J., and Frerman, F. E. 2010. The electron transfer flavoprotein: Ubiquinone oxidoreductases. Biochim. Biophys. Acta 1797: 1910-1916.

Weghoff, M. C., Bertsch, J., and Müller, V. 2015. A novel mode of lactate metabolism in strictly anaerobic bacteria. Environ. Microbiol. 17: 670-677.

Westhoek, A., Field, E., Rehling, F., Mulley, G., Webb, I., Poole, P. S., and Turnbull, L. A. 2017. Policing the legume-Rhizobium symbiosis: A critical test of partner choice. Sci. Rep. 7:1419-1429.

Xu, J., Webb, I., Poole, P., and Huang, W. E. 2017. Label-free discrimination of rhizobial bacteroids and mutants by single-cell raman microspectroscopy. Anal. Chem. 89:6336-6340.

Zamorano-Sánchez, D., Reyes-González, A., Gómez-Hernández, N., Rivera, P., Georgellis, D., and Girard, L. 2012. FxkR provides the missing link in the fixL-fixK signal transduction cascade in Rhizobium etli CFN42. Mol. Plant-Microbe Interact. 25:1506-1517. 